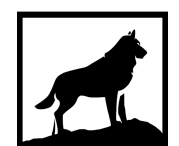

Michigan Technological

1 в 8 5 University
Michigan Technological University Digital Commons @ Michigan Tech

ASSESSING SOIL COMPACTION FOLLOWING A WINTER TIMBER HARVEST IN THE WESTERN UPPER PENINSULA OF MICHIGAN

Rafia Rahman

Michigan Technological University, rafiar@mtu.edu

Copyright 2019 Rafia Rahman

Recommended Citation

Rahman, Rafia, "ASSESSING SOIL COMPACTION FOLLOWING A WINTER TIMBER HARVEST IN THE WESTERN UPPER PENINSULA OF MICHIGAN", Open Access Master's Thesis, Michigan Technological University, 2019.

https://doi.org/10.37099/mtu.dc.etdr/922

Follow this and additional works at: https://digitalcommons.mtu.edu/etdr

Part of the Forest Management Commons 


\title{
ASSESSING SOIL COMPACTION FOLLOWING A WINTER TIMBER HARVEST IN THE WESTERN UPPER PENINSULA OF MICHIGAN
}

\author{
By \\ Rafia Rahman \\ A THESIS \\ Submitted in partial fulfillment of the requirements for the degree of \\ MASTER OF SCIENCE \\ In Forest Ecology and Management
}

MICHIGAN TECHNOLOGICAL UNIVERSITY

2019

(C) 2019 Rafia Rahman 
This thesis has been approved in partial fulfillment of the requirements for the Degree of MASTER OF SCIENCE in Forest Ecology and Management.

College of Forest Resources and Environmental Science

Thesis Advisor: $\quad$ Matthew C. Kelly

Committee Member: Evan S. Kane

Committee Member: $\quad$ Zhen Liu

College Dean: Andrew J. Storer 


\section{Table of Contents}

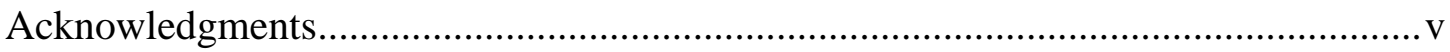

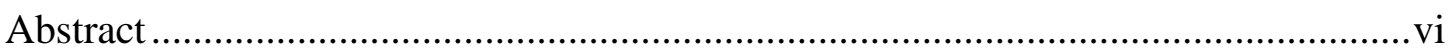

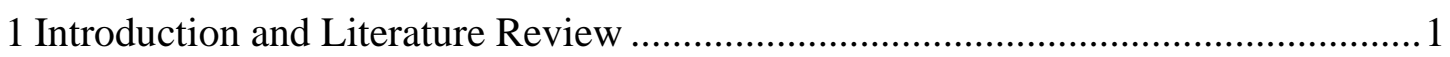

1.1 Soil Compaction and Timber Harvesting .................................................................. 1

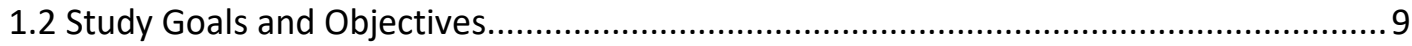

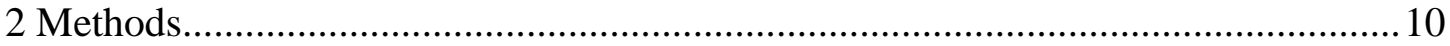

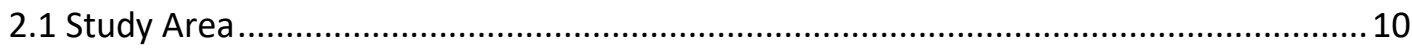

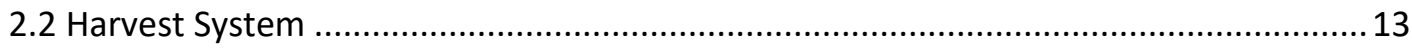

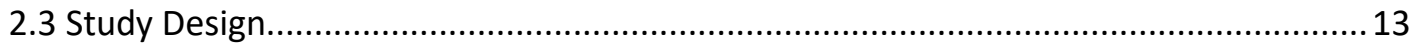

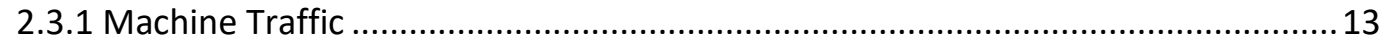

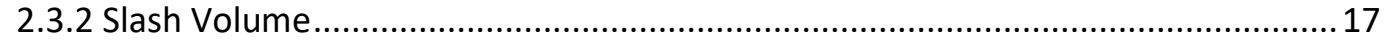

2.3.3 Percent Rock Content ........................................................................................... 19

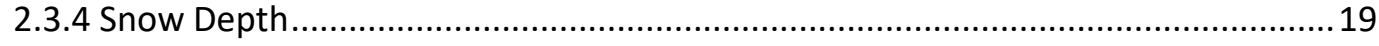

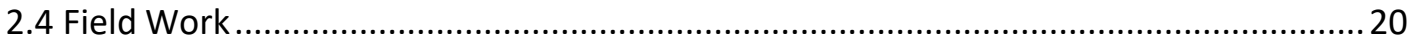

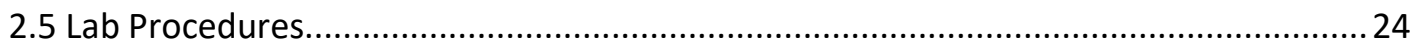

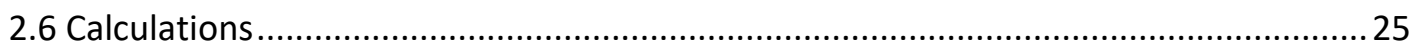

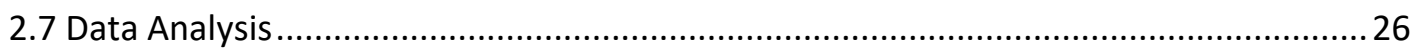

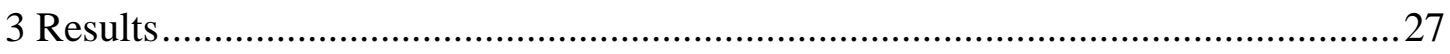

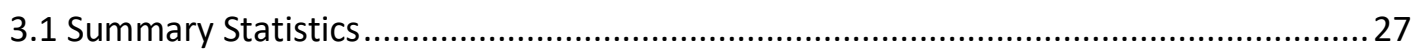

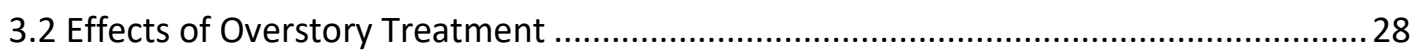

3.3 Effect of 6-Wheeled vs 8-Wheeled Machines....................................................................... 29

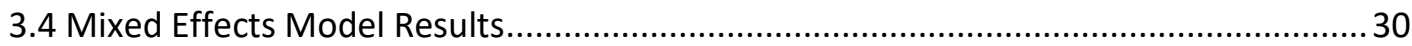

3.4.1 Effect of Traffic Intensity on Bulk Density.......................................................... 30

3.4.2 Effect of Rock Content on Bulk Density .............................................................. 32

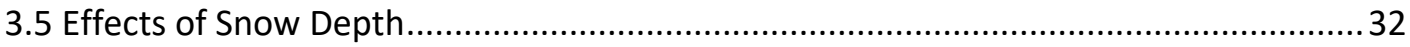

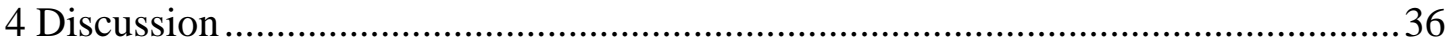

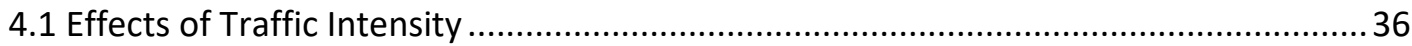

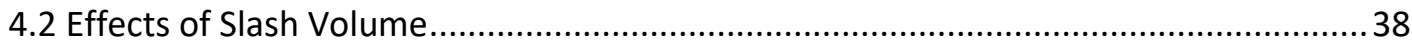

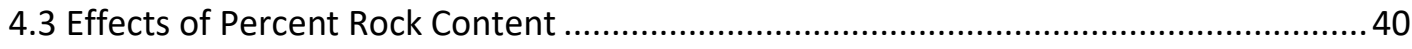

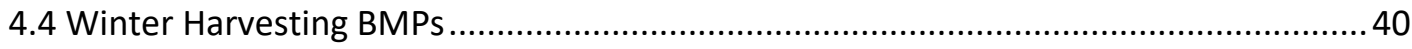

4.5 Limitations and Future Research ........................................................................... 41

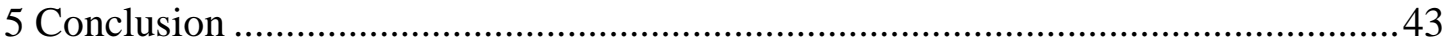

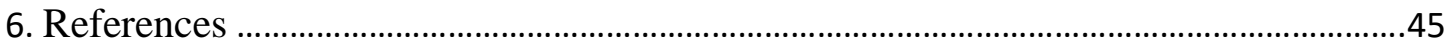




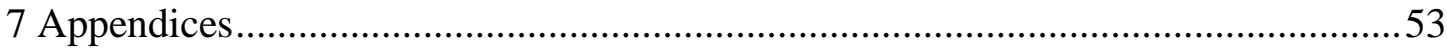




\section{Acknowledgments}

I'd like to first acknowledge the McIntire Stennis Program, from the USDA National Institute of Food and Agriculture for the funding they provided for this research. I express my deep sense of gratitude, sincere appreciation and profound regards to my reverend teacher and research supervisor Dr. Matthew C. Kelly, Assistant Professor, College of Forest Resources and Environmental Science, Michigan Technological University for his scholastic guidance, constant advice, innovative suggestions, constant supervision and inspiration, and helpful criticism in carrying out the research work and preparation of this thesis.

I deem it proud gratitude and regards to my thesis committee, Dr. Evan S. Kane, Associate Professor, College of Forest Resources and Environmental Science, Michigan Technological University and Dr. Zhen Liu, Associate Professor, Civil, and Environmental Engineering, Michigan Technological University for their constructive suggestions and necessary co-operation.

I am very grateful to my colleague Alex Helman for his help during field work. Finally, I express my heartiest gratitude to my parents for their blessings, inspiration, moral, cooperation and endless love throughout my life to reach up to this level. 


\begin{abstract}
Harvesting during winter is encouraged as a best management practice to protect soil during logging operations. The western Upper Peninsula of Michigan typically experiences early and persistent snowfall, which insulates the forest floor and prevents soils from freezing. The objective of this study is to assess the effects of slash volume, snow depth, overstory treatment, and machine traffic intensity on soil bulk density following a winter harvest of a northern hardwood forest on cobbly silt-loam soils. The harvest was conducted at the Ford Forest in Alberta, Michigan using cut-to-length harvest systems (i.e. harvester and forwarder) during which the soil remained unfrozen. Four levels of machine traffic (high, medium, low, none) and two levels of overstory treatment (clear-cut and partial cut) were considered within a factorial experimental design. Samples were extracted using coring cylinders and separated into three depths $(0-5,5-10,10-20 \mathrm{~cm})$ prior to drying, sifting and weighing. Results indicate that bulk density did not differ between the no traffic treatment and low traffic treatment at the $0-5 \mathrm{~cm}$ depth. However, soil bulk density for the no-traffic treatment was significantly lower than soil bulk density for the medium and high traffic treatments at the $0-5 \mathrm{~cm}$ depth. There was a significant effect for traffic in all depths, fine and full soil, except for the 5-10 fine and full soil (which had a p-value of .06). No significant effects of slash volume or snow depth were detected but there was significant effect of percent rock at each depth.
\end{abstract}




\section{Introduction and Literature Review}

\subsection{Soil Compaction and Timber Harvesting}

Soils provide many important functions within a forest ecosystem. They are a source of essential nutrients not only for individual trees but also for the overall forest ecosystem (Dominati et al. 2010). They also provide anchorage and available water necessary to support tree growth. However, soil properties, including soil structure, can be altered by anthropogenic and natural disturbances such as erosion, timber harvesting, prescribed burning, or wildfire (Elliot et al. 1998).

Disturbance from logging can have significant impacts on soils. In recent decades, mechanized harvest systems have become popular because of their improved productivity relative to hand felling systems and the benefits for worker safety (Cambi et al. 2015). Harvest machines, including harvesters, fellerbunchers, skidders, and fowarders, are commonly used to fell, transport and process timber for various purposes (Simmons, 1951; Akay and Sessions, 2001; Greene et al. 2013). Mechanized harvests can impact soil due to the high ground pressures exerted by these modern logging machines (McDonald et al. 1995; McNabb et al. 2001). As axle load capacities increase, machines are becoming capable of supporting greater weight (Håkansson and Reeder, 1994).

A specific concern associated with mechanized harvesting is soil compaction. According to Coder (2000), the definition of soil compaction is the translocation and resorting of textural components in the soil (sand, silt, and clay particles), destruction of soil aggregates, and collapse of aeration pores. Changes in bulk density is commonly used to measure soil compaction. In general, bulk density $\left(\mathrm{g} / \mathrm{cm}^{3}\right)$ increases as pore space decreases 
(Figure 1). Finer texture soils, such as silt and clay, generally have more pore space and thus have lower bulk density than sandy soils (Source: DeJong-Hughes 2018).
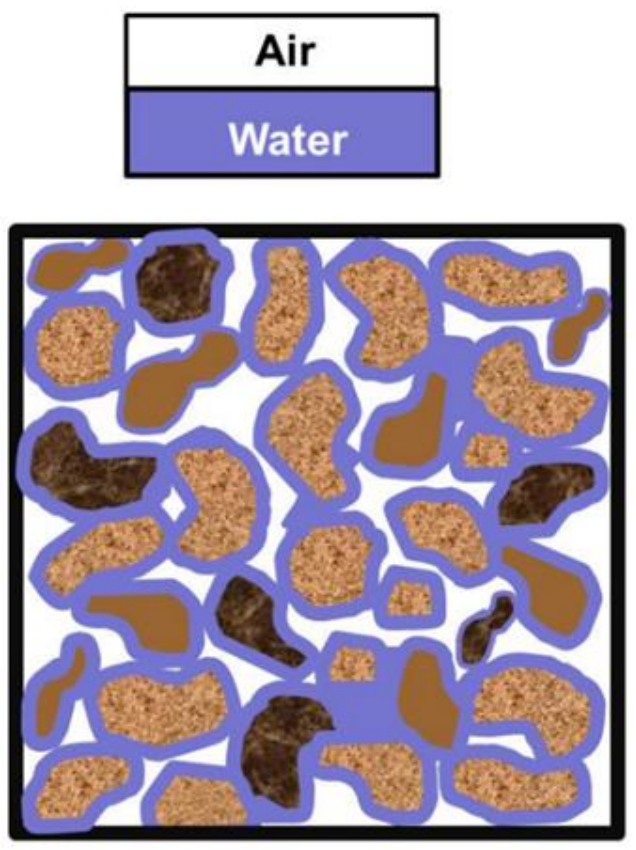
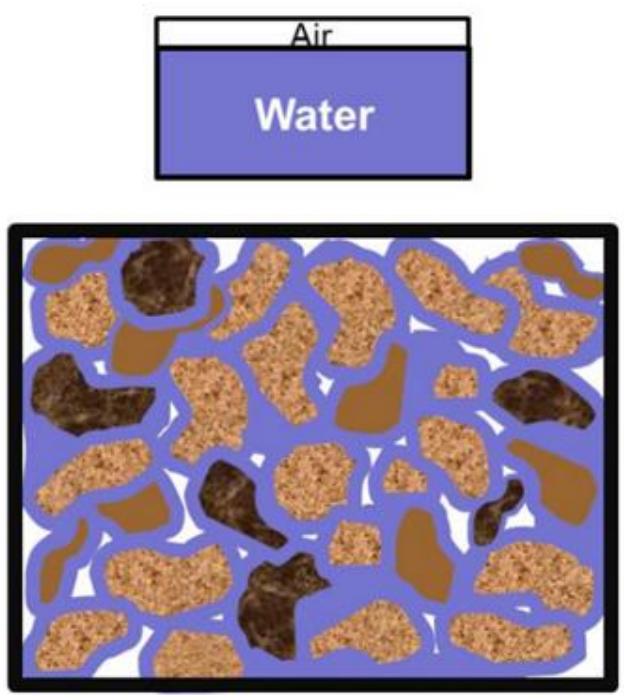

Figure 1. Physical effects on soil due to compaction (DeJong-Hughes, 2018)

Compaction decreases air and water availability to plant roots and microscopic organisms as well (Bodelier et al. 1996; Startsev and McNabb, 2000; Frey et al. 2009). Soil compaction changes soil physical properties and structure, decreases pore space and saturated hydraulic conductivity (Jansson and Johansson, 1998; Grace et al. 2006), and affects site quality by reducing the rate of water penetration and aeration of soil, and can increase resistance to root penetration (Greacen and Sands,1980; Taylor \& Brar 1991; Quesnel and Curran, 2000; Grigal 2000; Zhao et al. 2010) and can eventually restrict plant growth (Kozlowski, 1999; Meyer et al. 2014). Recovering adequate pore space, water availability, and rich organic matter content after compaction can take long periods of time, ranging from an estimated seventy to one hundred forty years depending on variables such as climatic conditions, type 
of soil and degree of compaction (Greacen \& Sands, 1980; Froehlich et al. 1985; Webb et al. 1986). Addditionaly, harvesting disturbances can affect tree regeneration success by damaging tree roots, decreasing root respiration, and limiting the active rooting zone as well as root growth and development (Hatchell et al. 1970; Martin, 1988).

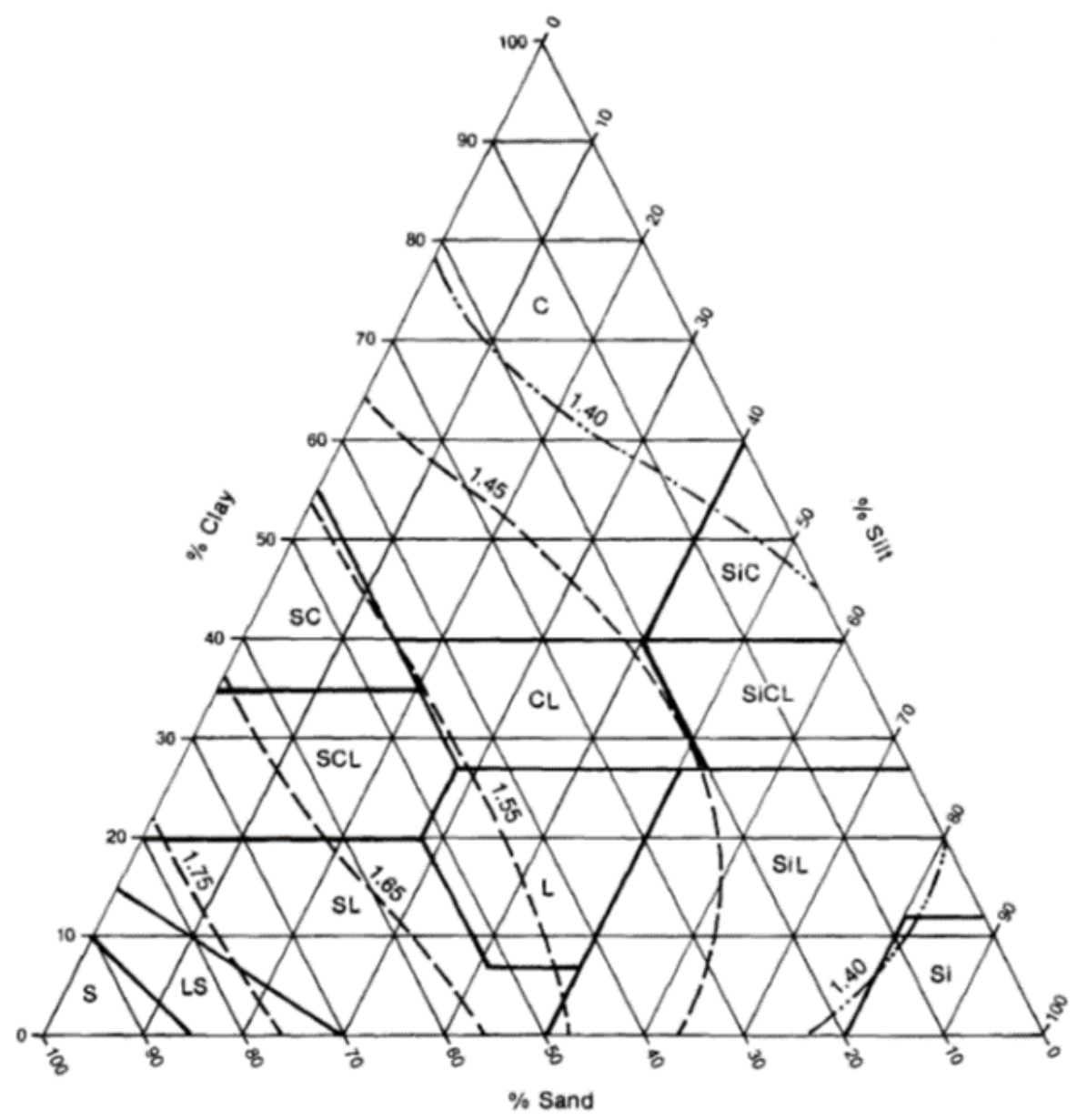

Figure 2. Growth-limiting bulk density $\left(\mathrm{g} / \mathrm{cm}^{3}\right)$ textural triangle (source: Daddow and Warrington, 1983) 
The degree to which soil is compacted depends on numerous factors such as machine traffic intensity, slope steepness, site characteristics, harvesting machinery type, designing or planning of skid roads, and the caution and expertise of machine operators (Reisinger et al. 1992; Laffan et al. 2001; Eliasson and Wa“sterlund 2007; Demir et al. 2007; Najafi et al. 2009; Solgi and Najafi 2014; Naghdi and Solgi 2014; Cambi et al. 2015). Additionally, soil deformation is linked to soil moisture, initial bulk density, soil organic matter, and ground elevation (Ballard, 2000; Jamshidi et al. 2008). Generally, soils with low bulk density are more susceptible to compaction (Hillel, 1998; Williamson and Neilsen, 2000; Powers et al. 2005). Soils which have bulk densities $\geq 1.4 \mathrm{Mg} \mathrm{m}-3$ are not that much affected by compaction. Although tree growth can be reduced due to compaction on clayey soils, Powers et al (2005) found compaction benefited tree growth in sandy soils due to increased water and nutrient availability.

Machine traffic intensity (the number of machine passes on a skid trail due to tree harvesting) is a key factor in soil compaction as deformations generally increase with the increasing number of passes and may eventually lead to significant disturbance of soil (Mosaddeghi et al. 2000; Solgi and Najafi 2014).

The relationship is nonlinear between soil bulk density and traffic intensity (McNabb et al. 1997; Najafi, 2010), such that the first few passes are generally responsible for most surface compaction, but bulk density may increase with increasing traffic over the site according to the number of passes and soil depth (Hatchell et al. 1970; Brais and Camire', 1998; Williamson and Neilsen, 2000; McNabb et al. 2001). Traffic intensity over a given skid trail can be measured using GPS technology (McMahon, 1997; Carter et al. 1999; McDonald et al. 2002). GPS units can be attached to each machine to track machine 
movement. Those data can then be analyzed to determine the number of passes over a given skid trail within ArcMap so that the affected areas can be identified (Zenner et al. 2007).

In temperate forests, harvesting in winter is typically encouraged as a best management practice to protect soils, particularly those composed mainly of finer texture silt or clay soils. Thus summer logging is generally not recommended on sensitive or poorly dained soils (Smith and Wass, 1976; Krag et al. 1986). When harvesting forested wetlands, harvesting in the winter under frozen conditions is necessary to prevent negative impacts to these sensitive areas (Zasada et al. 1987).

Similarly, placing slash (i.e. logging residue in the form of tree tops and limbs) on skid trails is encouraged to reduce soil disturbance, including compaction, erosion and surface runoff (Sawyers et al. 2012; Wade et al. 2012; Vinson et al. 2017). Slash can also play an important role for improving site quality by providing an organic layer for natural tree regeneration (Eisenbies et al. 2005), and reducing compaction caused by heavy forestry machines (Parkhurst, 2018). For erosion control, slash application is recommended (Virginia Department of Forestry [VDOF] 2011; Wade et al. 2012; Vinson et al. 2017). Eliasson and Wästerlund (2007) found that topsoils of strip roads in which slash was established did not incur any damage from compaction. On the other hand, McDonald and Seixas (1997) found that slash did not reduce compaction on sandy soil after the first pass of a rubber-tired forwarder.

Differences in silvicultural techniques applied during harvesting can produce different levels of slash due to differences in harvest intensity, particularly in terms of the amount 
of trees cut per acre (or volume removed per acre). The type of silviculture treatment being applied can also affect machine traffic intensity.

Bigelow et al. (2018) applied three different selection methods in longleaf pine forest on coarse-textured soils including single-tree, group, and group with reserved trees. The authors found that according to the single-tree selection system, a greater area was affected by single machine passes than higher numbers of passes, on the other hand under group and group with reserves selection system more area was affected by high traffic areas. Malo and Messier (2011) studied the effect of two type of machine tracks primary (multiple trip) and secondary (only one trip) followed by a silvicultural system (selection cutting) to evaluate sugar maple (Acer saccharum Marsh.) fine root growth and reported that heavy machinery has an effect on physiological structure, growth and development of sugar maple one year after the silvicultural operation (selection logging) was completed. It was found from the data that the control area was less affected than both primary and secondary tracks for the fine root growth of sugar maple.

Stone (2002) conducted an experiment that examined the effects of winter logging on soil disturbance and regeneration success on clay soils of four aspen-dominated stands in Western Upper Michigan. The results showed that a large skidder was responsible for deep rutting on $20 \%$ of sites that received a thinning that removed $7.8 \mathrm{~m}^{2} \mathrm{ha}^{-1}\left(34 \mathrm{ft} 2 \mathrm{ac}^{-1}\right)$ of basal area, and on $38 \%$ of clearcut sites. The authors also found that $45 \%$ of clearcuts did not have aspen regeneration after the first growing season and $82 \%$ had less than the recommended minimum of 15,000 suckers ha-1 (6,000 ac-1).

Bates et al. (1993) carried out a study that looked at harvesting effects on quaking aspen regeneration in northern Minnesota and found that regeneration of aspen is affected by 
equipment traffic and harvest season. In that study, regeneration vigor associated with variables such as stem density, stem height growth, and crown closure, all of which were greater following winter harvesting. The authors also reported that aspen regeneration was reduced significantly following the summer harvesting and with increased traffic in the harvest sites. The results from this study suggest that comparatively fine-textured and poorly drained soils are more prone to regeneration problems for aspen once harvested initially in summer but the most vigorous regeneration happens following winter harvesting.

Zenner et al. (2007) also investigated soil disturbance due to ground-based logging operations within a quaking aspen stand. Different levels of traffic intensity were applied to measure effects of machine traffic on aspen regeneration, growth, recovery on this site as well as resistance capacity to penetration within the top $15 \mathrm{~cm}$ of soil for three years after clearcutting. The result showed that within the $0-5 \mathrm{~cm}$ depth, soil can recover from disturbance three years after the harvest, but partial recovery was found within the top $10 \mathrm{~cm}$ depth during four or less machine passes and recovery was very limited for 10-15 $\mathrm{cm}$ soil depth within a three-year period. Skidding traffic intensity significantly reduced height, density of aspen sucker, growth, dbh, and basal diameter compared with control areas but resistance to penetration was not significantly different.

Naghdi et al. (2018) found that machine traffic has an effect on soil pore space and bulk density. They sampled skid trails immediately after a skidding operation and again one year later to evaluate recovery of soil physical properties. The authors measured soil bulk density across three levels of traffic intensity and two levels of slope steepness. Data showed that bulk density and microporosity were greater due to the use of harvest 
machinery whereas microporosity and total porosity were less for top ten $\mathrm{cm}$ of soil depth compared with the areas that were not harvested. The compacted soil did not show any significant recovery after one year. Rather, further decrease in microporosity was reported. Williamson and Neilson (2000) studied soil compaction and how the soil profile can be disturbed in a skid trail due to the operation of heavy ground-based logging machines. Six forest areas (dry and wet forests) were selected to evaluate. The authors reported that compaction restricts root growth and reduces forest productivity. It was observed that machine forces displaced topsoils rather than causing compaction in situ on the wettest soils logged.

Parkhurst et al. (2018) conducted a study within a pine stand and observed that the heavier skidder was responsible for higher bulk density, reduced macroporosity, and more visible ruts than the lighter dozer and the amount of disturbance to a given site may increase with the increased machine size. They also found that providing slash cover had limited effect on changes in bulk density and porosity than using the forest floor for overland skidding. In addition, they found that mechanical resistance data contradicted the machine size finding because the effects from the heavy skidder and light dozer were similar in size in the surface depth category.

Zasada et al. (1987) showed that winter logging is suitable because accessing floodplains is easier during the winter season while logging, as well as transport, but during summer season these areas are not accessible when rivers and poorly drained areas are no longer frozen. They also observed that tree regeneration can be protected from physical damage by logging with a good snowpack as the upper layer of the snowpack was disturbed and mixed with logging debris, the lower part of the snowpack was compacted but not mixed. 


\subsection{Study Goals and Objectives}

The western upper peninsula of Michigan typically experiences early and persistent snowfall, which insulates the forest floor and prevents soils from freezing. This study was conducted to assess post-harvest soil compaction following a winter harvest of northern hardwoods on cobbly silt-loam soils. The harvest included both clearcuts and various partial cuts (e.g. shelterwood, singletree-selection). The cover type was northern hardwoods, with a very large component of sugar maple (Acer saccharum Marsh.). The objective of the study was to assess the effects of machine traffic, slash volume, snow depth, and percent rock content on soil bulk density following operation of a cut-to-length harvest system (i.e. harvester and forwarder) during which the soil remained unfrozen. 


\section{Methods}

\subsection{Study Area}

This study was conducted following a winter timber harvest at Michigan Technological University's Ford Forest, located in Alberta, Michigan during the months of February and March of 2017. This site consists primarily of northern hardwoods, dominated by sugar maple (Acer saccharum Marsh), with some yellow birch (Betula alleghaniensis), basswood (Tilia Americana), red maple (Acer rubrum), balsam fir (Abies balsamea), black cherry (Prunus serotine), ironwood (Ostrya virginiana), and american elm (Ulmus Americana).

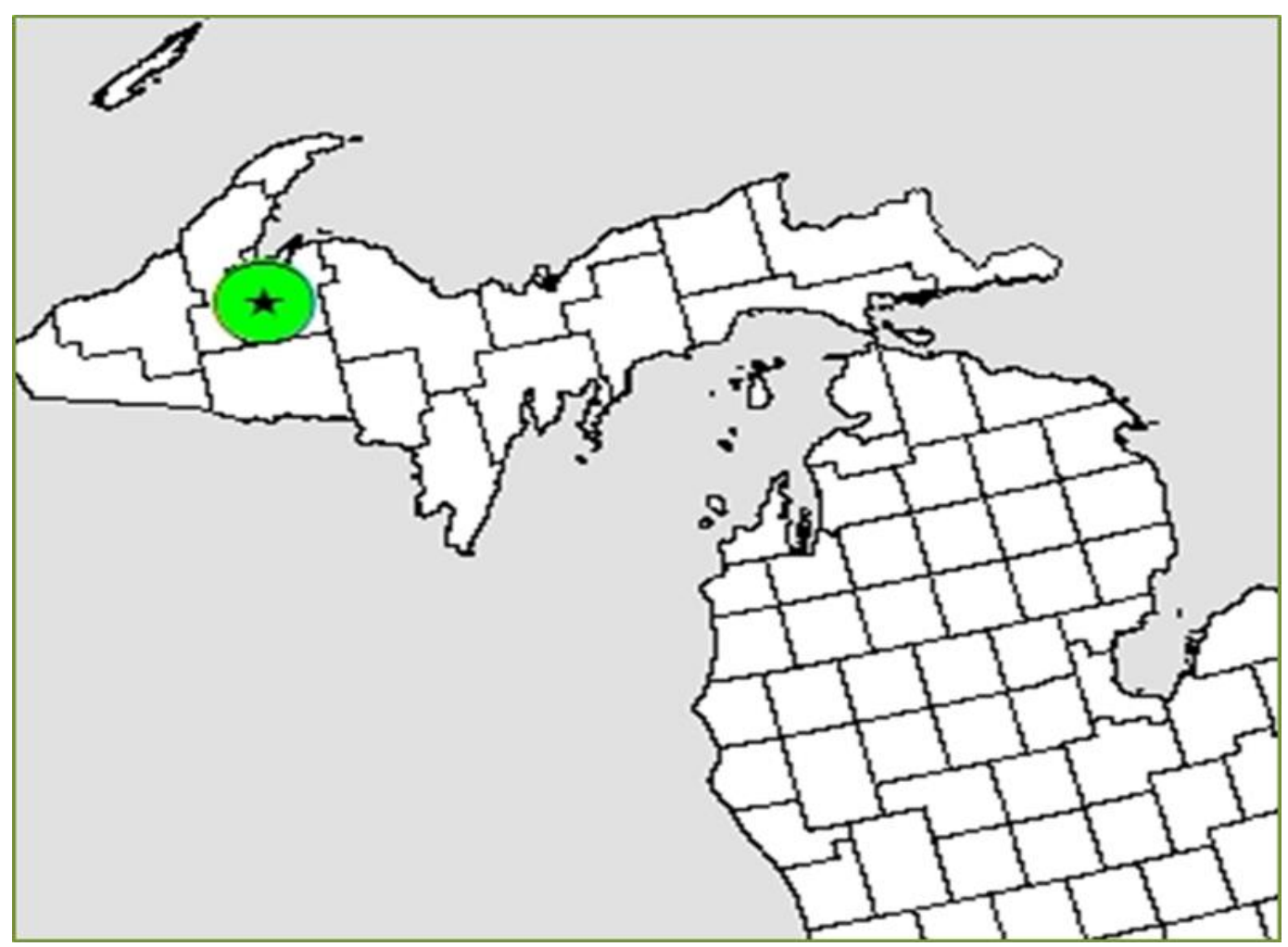

Figure 3. Study site located in Alberta, MI at Michigan Technological University's Ford Forest. 
The harvest occurred as part of the Northern Hardwood-Silvicultural Experiment for Enhancing Diversity (NH-SEED), which included both clearcuts and various partial cuts (e.g. shelterwood, singletree-selection).

The site consists mainly of the Champion soil series (taxonomic class: coarse-loamy, mixed, superactive, frigid Oxyaquic Fragiorthods), with relatively small areas of Tacoosh, Witbeck, and Michigamme soils series (Figure 4). The champion series is characterized by well-drained to moderately well-drained cobbly silt loam soils. According to the Natural Resources Conservation Service, gravel content ranges from 0 to $10 \%$ for A, E, and B horizons; and from 5 to $35 \%$ in the $2 \mathrm{~B}$ and $2 \mathrm{C}$ horizons whereas cobble and stone content range from 0 to $35 \%$ for $\mathrm{A}, \mathrm{E}$, and $\mathrm{B}$ horizons and from 0 to $15 \%$ in the $2 \mathrm{~B}$ and $2 \mathrm{C}$ horizons. The Michigamme series consists of moderately deep, well-drained soils that are formed by igneous or metamorphic bedrock. In this soil series, the upper part of the solum is moderately permeable but slow or very slow in the lower part.

According to the National Oceanic and Atmospheric Administration (NOAA), during winter, average minimum temperature is about $7.1^{\circ} \mathrm{F}$, and the average maximum temperature is $23.7^{\circ} \mathrm{F}$. Weather data for this study site during the harvest period, which started Feb 6, 2017, and ended March 26, 2017, varied on a daily basis. The average snowfall was 0.75 inch per day within the period. Snow depth data was also collected for each day during the harvest where the average snow depth was about 11 inch. The range of snow depth was recorded from 1 to 27 inch and the maximum snow depths were found at the beginning of the harvest time and these data were collected also before the machine passes and became lower during the last days in March. The average data were found for maximum and minimum temperatures of about $31.7^{\circ} \mathrm{F}$ and $13.5^{\circ} \mathrm{F}$. 


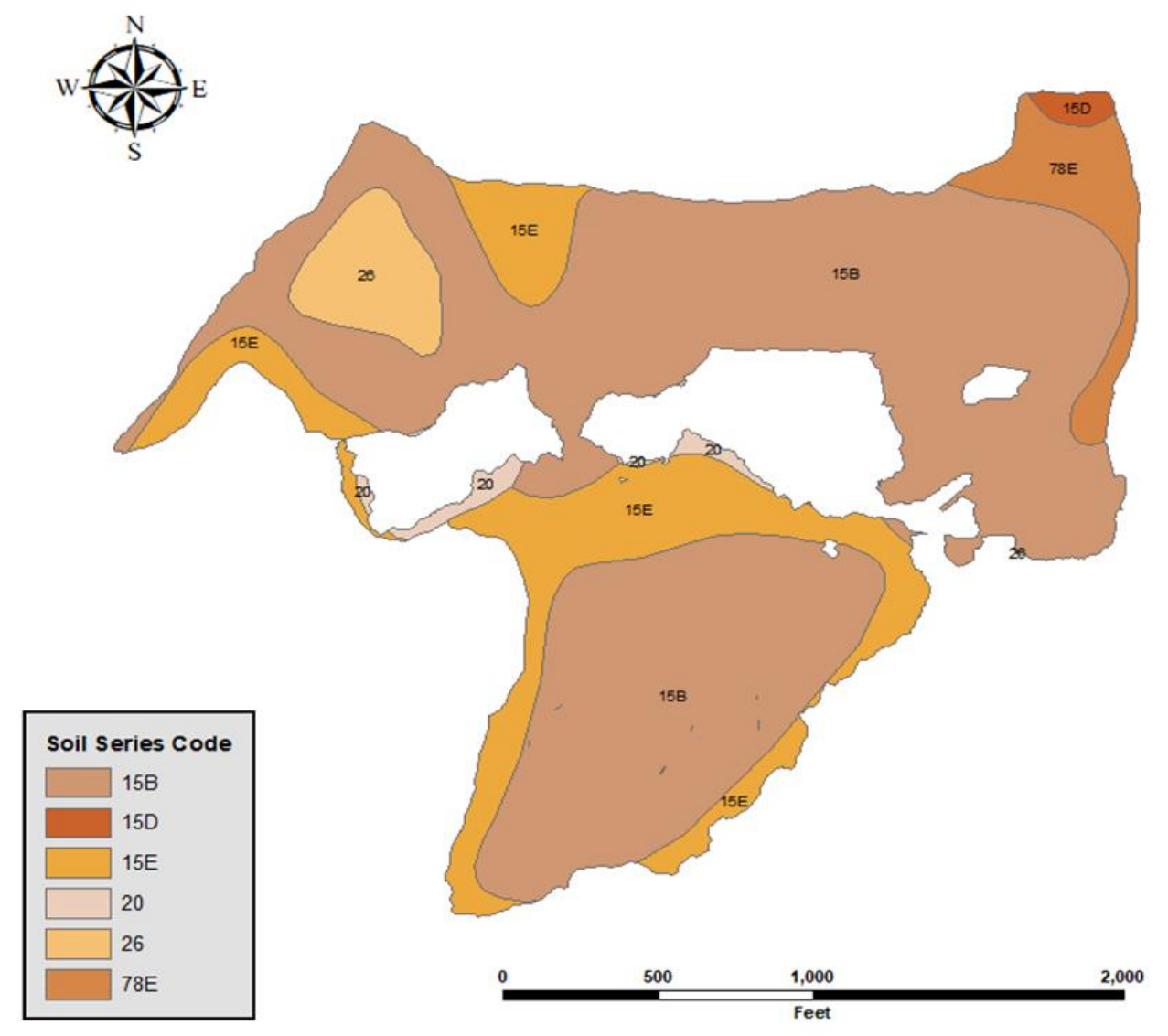

Figure 4. Soil series map for Study area (Source: WSS, NCRS-USDA), where 15B= Champion cobbly silt loam with 1 to $8 \%$ slope, $15 \mathrm{D}=$ Champion cobbly silt loam with 8 to $15 \%$ slopes, $15 \mathrm{E}$ $=$ Champion cobbly silt loam with the slope range of 15 to $35 \%, 20=$ Carbondale and Tacoos muck with 0 to $1 \%$ slopes, $26=$ Witbeck muck with 0 to $2 \%$ slopes, $78 \mathrm{E}=$ Champion-Michigamme cobbly silt loams with 15 to $35 \%$ slopes 


\subsection{Harvest System}

The harvest was conducted using two cut-to-length harvest systems, each comprising a harvester and a forwarder. The two harvesters were different, one was a 6-wheeled PONSEE Bear and the other was an 8-wheeled PONSEE Ergo. The harvester fells trees and processes them into logs and the forwarder transports the logs from the harvest area to the road or landing, where they are picked up by a log truck and brought to a mill.
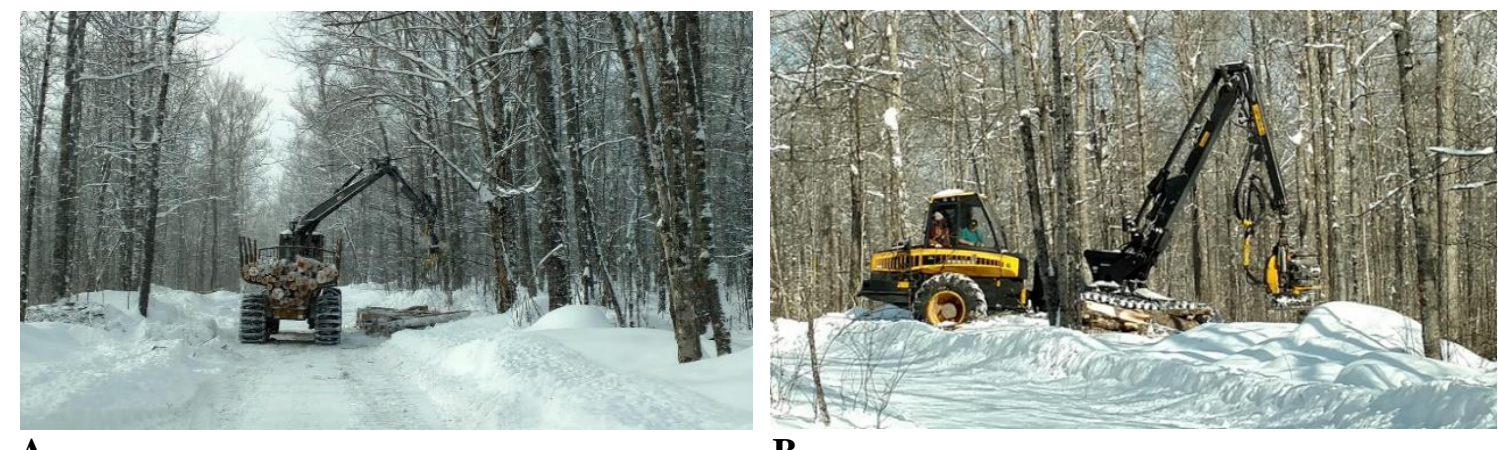

B

Figure 5. A showing a forwarder as part of a cut to length system and $\mathbf{B}$ showing a harvester (PONSEE bear)

\subsection{Study Design}

Soil samples were collected from ford forest, Alberta, MI and later analyzed to measure the effects of various factors on soil bulk density. Those factors include machine traffic, slash volume, rock content, and snow depth, and are explained in greater detail below.

\subsubsection{Machine Traffic}

GPS units were used to collect waypoints every 3 seconds for each harvest machine during the entire harvest. Those GPS data were then used within an ArcGIS to analyze the number of passes over a given skid trail. Six sample plots were established for each level of machine traffic (3) within each type of overstory treatment (2) resulting in 18 total plots. 
Each plot was defined as a section of skid trail $20 \mathrm{~m}$ in length. Machine traffic was defined in terms of number of machine passes and grouped into three categories:

- High traffic ( $>=8$ passes $)$

- Medium Traffic (4-7 passes)

$\circ \quad$ Low traffic (1-3 machine passes)

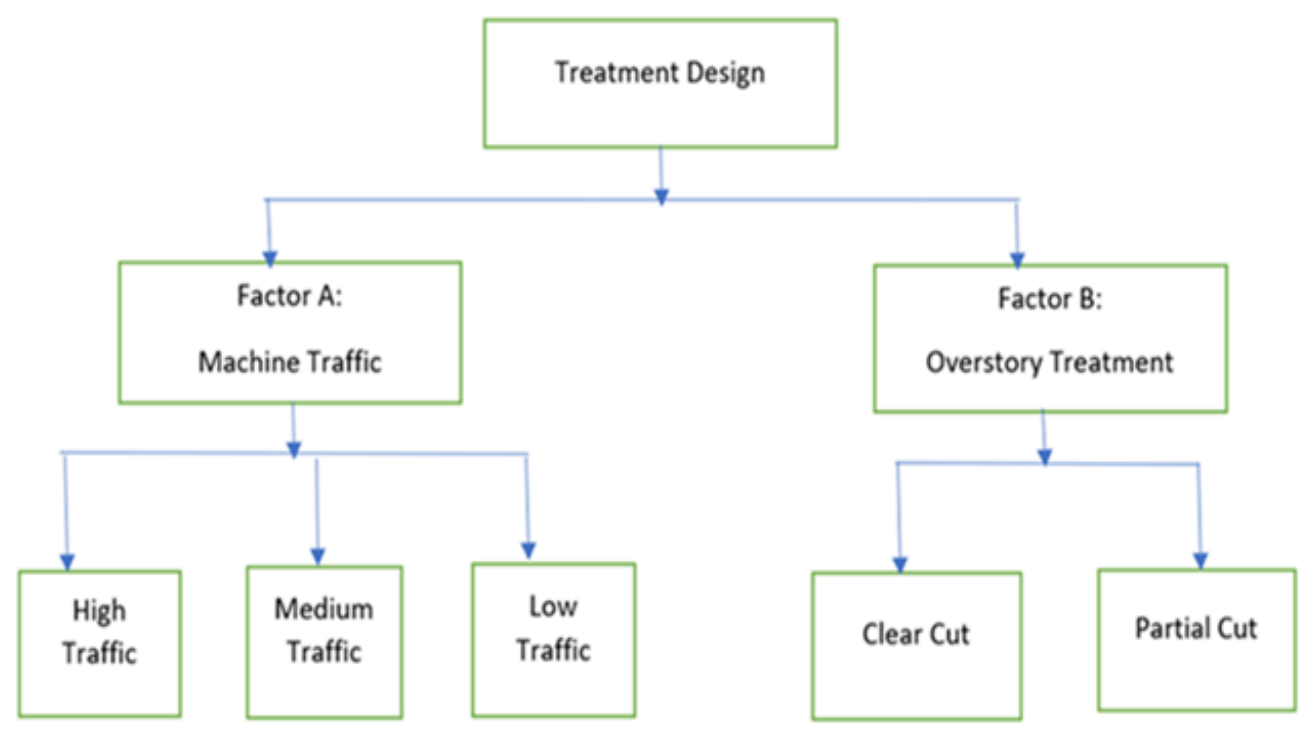

Figure 6. Treatment design of this research where factor A represents three levels of machine traffic and factor B represents overstory treatment with clearcut and partial cut 


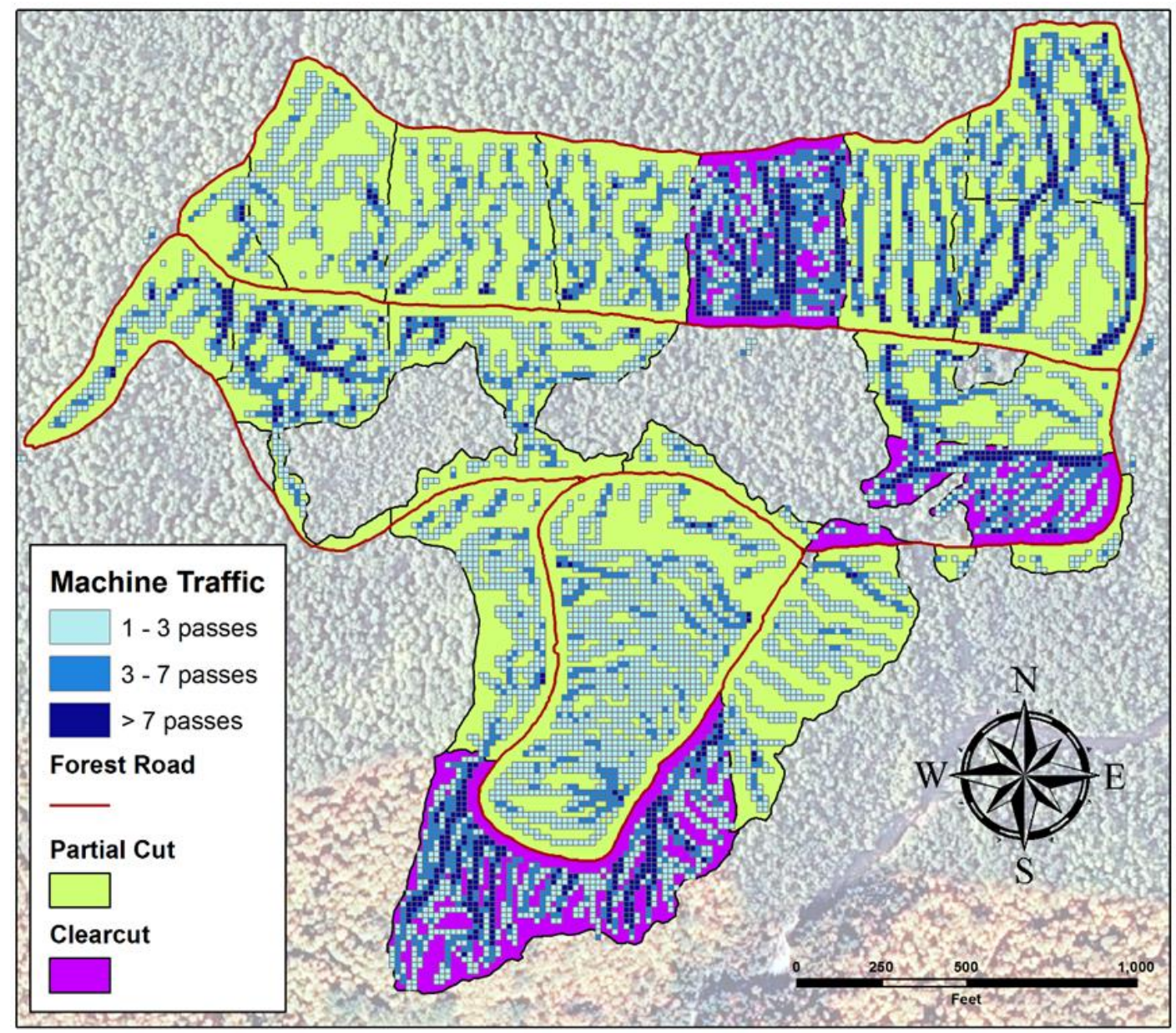

Figure 7. Showing all skid trails and the different levels of traffic (high, medium, low)

Sample plots were stratified equally into one of two overstory treatments - partial cut and clearcut. Stratifying the sampling by overstory treatment was meant to account for potential differences in slash volume. All segments of skid trails were identified and partitioned into 20 -meter segments. Next, three segments were selected randomly from the total population of skid trail segments for each combination of machine traffic level and overstory treatment. The random selection was done using a random number generator within MS Excel. 


\section{NH-SEED Soil Sampling Plots}

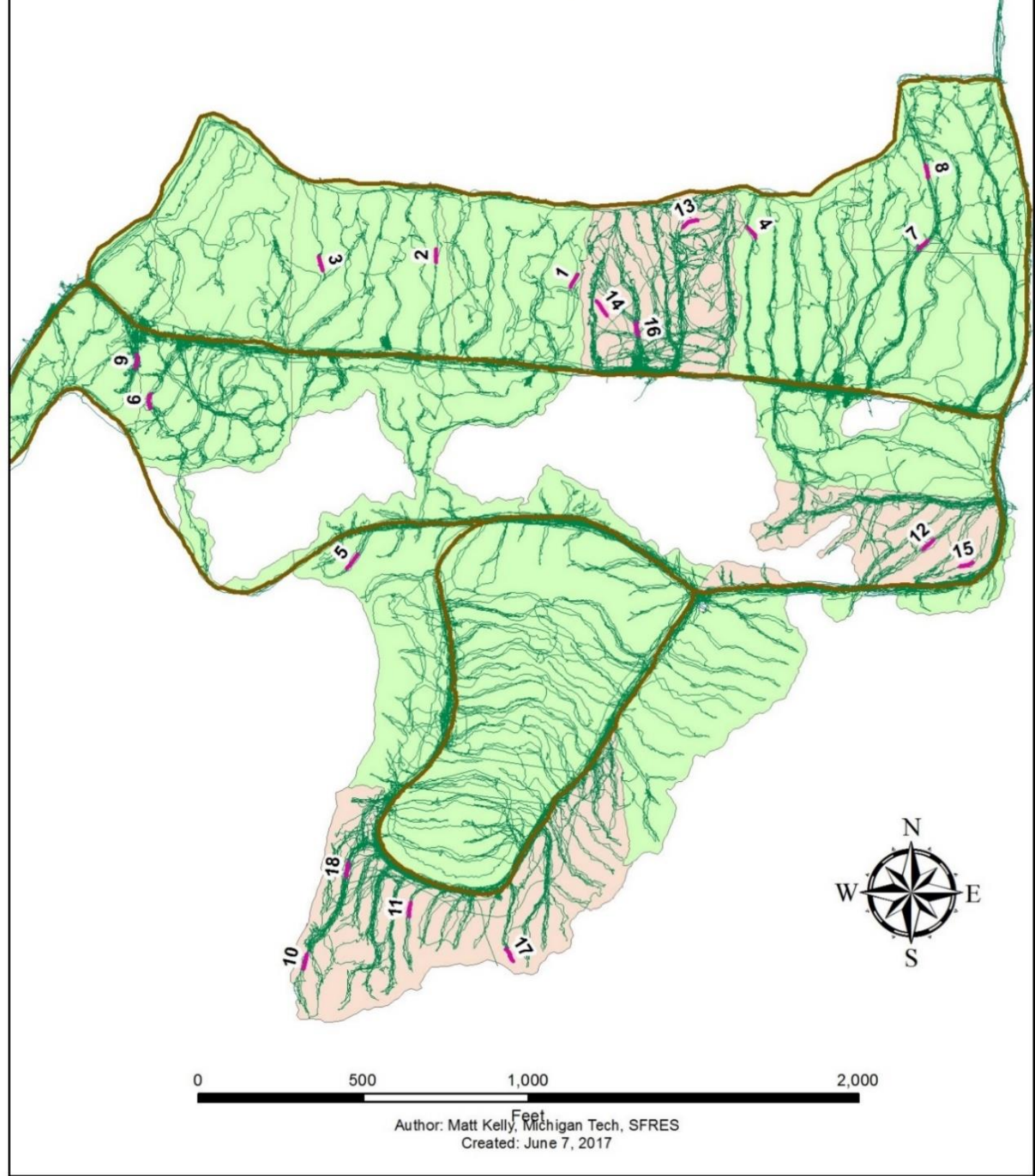

Figure 8. Map showing the location of the study site with the sample plots. 
Within each plot, 6 sample points were located along each side of the skid trail, within the tire tracks, for a total of 12 points per plot. Points were spaced two meters apart. Additionally, 31 samples were collected randomly from locations within the harvest area where machines did not travel. These areas were identified within ArcGIS as areas where no machines traveled, according to the GPS data. Thus, these samples represent a "no traffic" treatment level.

\subsubsection{Slash Volume}

Slash is defined as woody debris from unutilized tree limbs and tops that were either intentionally placed on the skid trail or happened to fall on the skid trail during the harvest operation. Slash volume was measured by first visually estimating a packing ratio of woody material within a three-dimensional space over a square meter area surrounding the sample point. To estimate the volume of the three-dimensional space over a given point, a square meter quadrat was used to establish length and width, while the height of the highest piece of woody material within the quadrat was used to estimate the total volume of the space.

Packing ratios were visually estimated with the help of a field guide. The field guide included images of six different levels of slash volume for which volumes and packing ratios were fully measured. The field guide was developed prior to sampling. At each of the six points chosen to create the field guide, height of the highest piece of slash within the square-meter quadrat was measured. Next, all slash within the quadrat was cut, removed, and weighed using a luggage scale. Thus, for each of the six representative plots, the density of slash was measured in units of $\mathrm{m}^{3} / \mathrm{m}^{2}$. 
Next, this density was compared to the density of sugar maple wood with 23 percent moisture content (MC), which is roughly $706.5 \mathrm{~kg} / \mathrm{m} 3$ (Simpson and TenWolde, 1999). This MC represented the mean MC of all wood samples measured in the field during the development phase of the field guide using a handheld moisture content meter. Therefore, the packing ratio was the ratio of the measured slash density to $706.5 \mathrm{~kg} / \mathrm{m} 3$.

The images and measured packing ratios found in field guide were used to help visually estimate packing ratio for each sample point. This estimated packing ratio was then applied to the three-dimensional space above square meter, as determined by the height of the highest piece of woody debris, to calculate slash volume in terms of $\mathrm{m}^{3} / \mathrm{m}^{2}$.
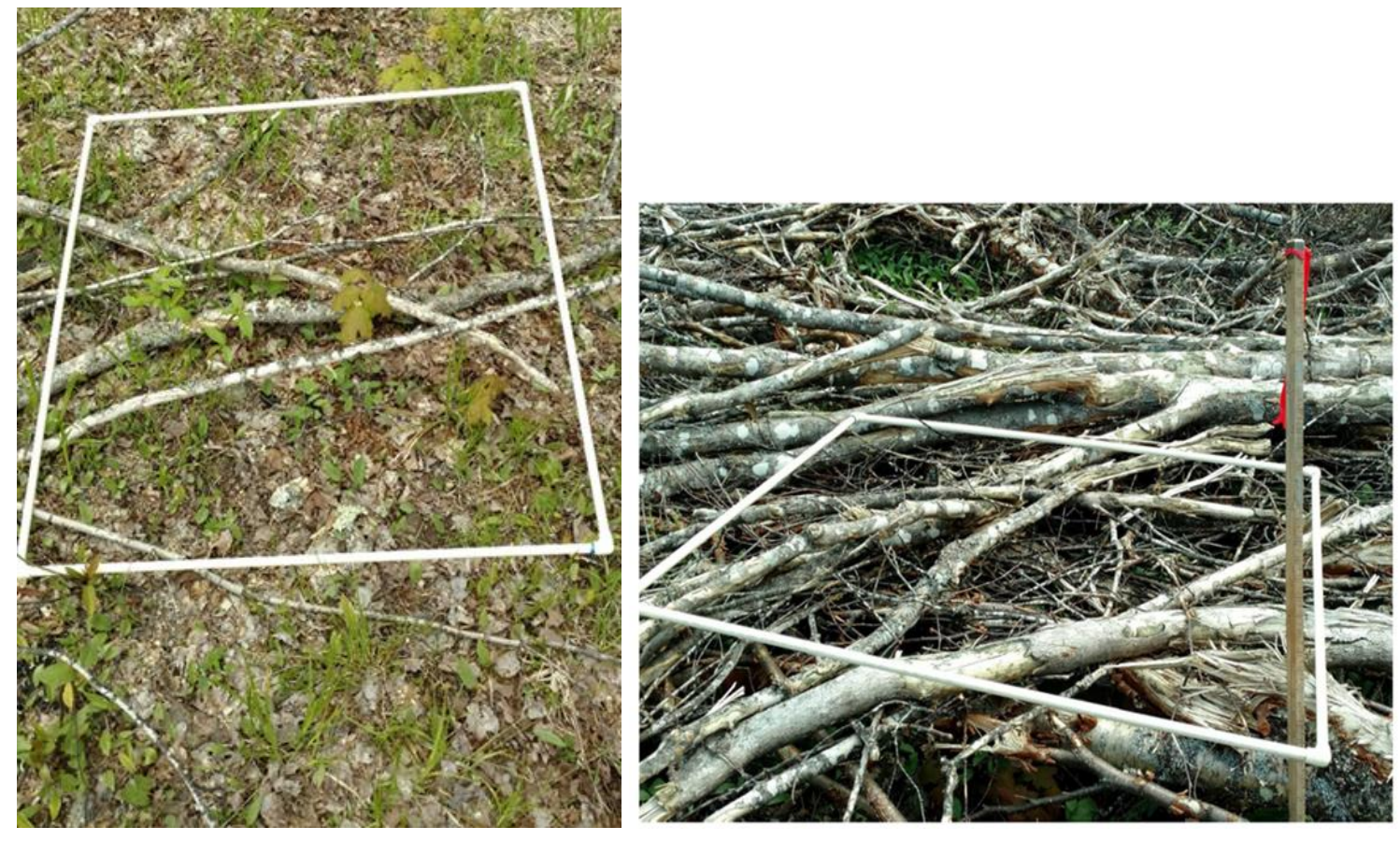

A

B

Figure 9. Estimating the packing ratio using a square meter quadrat and packing ratio field guide was developed by calculating packing ratio as volume of slash / volume of 3-dimensional space to use as a reference later for each sample point 


\subsubsection{Percent Rock Content}

Rock has density of $2.65 \mathrm{~g} / \mathrm{cm} 3$ (NRCS, USDA). It was reported that rock fragment content negatively influences fine soil bulk density (Stewart et al. 1970; Torri et al. 1994). Therefore, percent rock content was measured for this study to identify potential effects of rock content on soil bulk density in different depth of soil $(0-5 \mathrm{~cm}, 5-10 \mathrm{~cm}, 10-20 \mathrm{~cm})$. Additional Data related to rockiness were collected during field sampling which includes number of attempts at each sample point, depth to rock or root obstruction for each failed attempt, number and percent cover of surface rocks within a square meter plot around the sample point.

\subsubsection{Snow Depth}

Daily snow depth data collected in the village of Alberta, MI and reported to NOAA were used to assess impacts of snow depth on soil bulk density. The snow depth on the day that a skid trail was first traversed, according to the GPS data, was used for all samples in a given plot. Snow depth was generally greatest at the start of the harvest, but decreased substantially at various point throughout the harvest due to periods of warm temperatures (Appendix 16) 


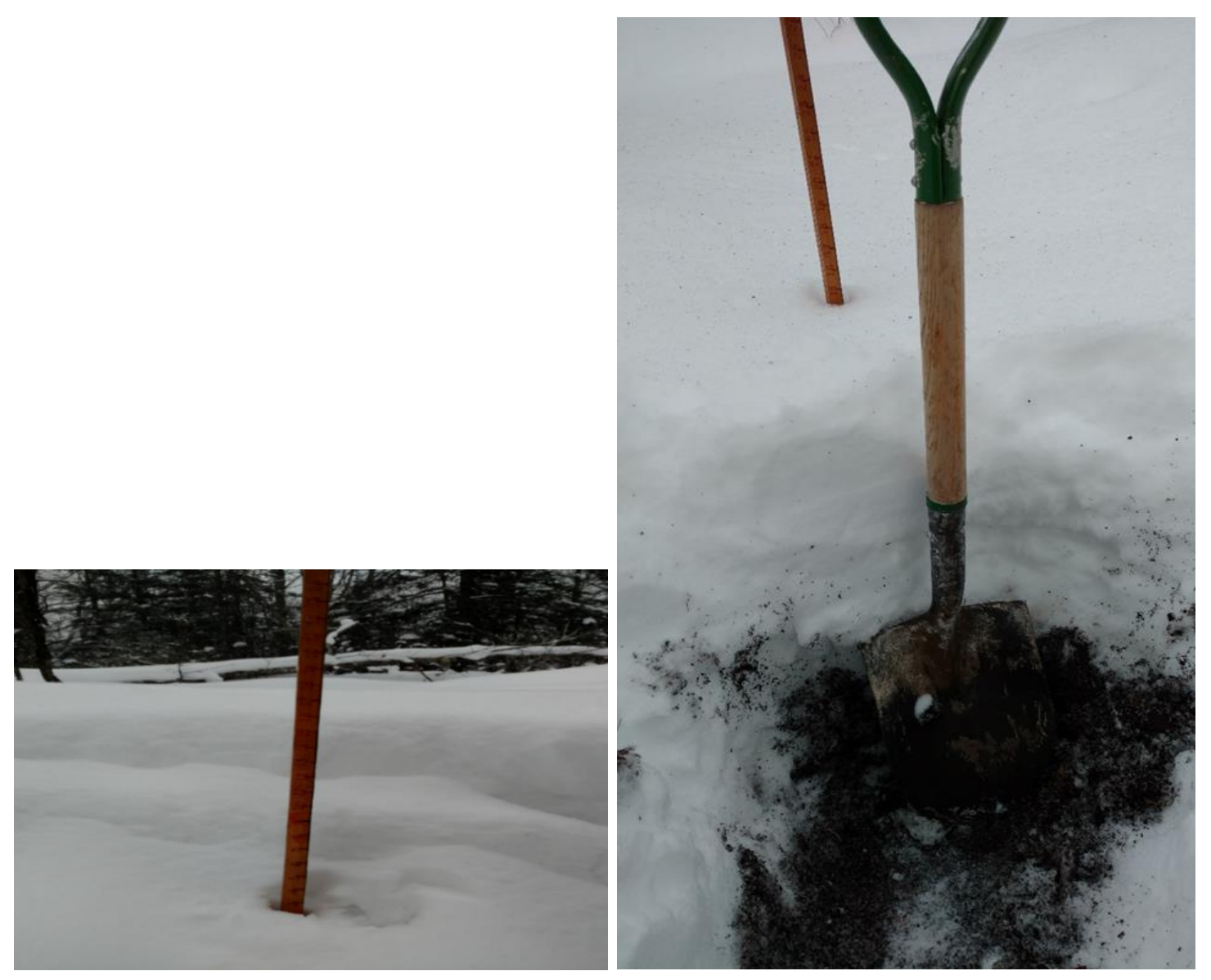

Figure 10. Representation of snow depth and the underlying unfrozen soil during one of the harvest days

\subsection{Field Work}

At each sample point, soil was extracted using a slide hammer and a $20 \mathrm{~cm}$ x $5 \mathrm{~cm}$ core sampler. The sample was divided into three depths using liners that fit within the cylinder. Soils within each depth were placed into plastic bags labeled with the plot and point number, and the soil depth $(0-5 \mathrm{~cm}, 5-10 \mathrm{~cm}, 10-20 \mathrm{~cm})$. 


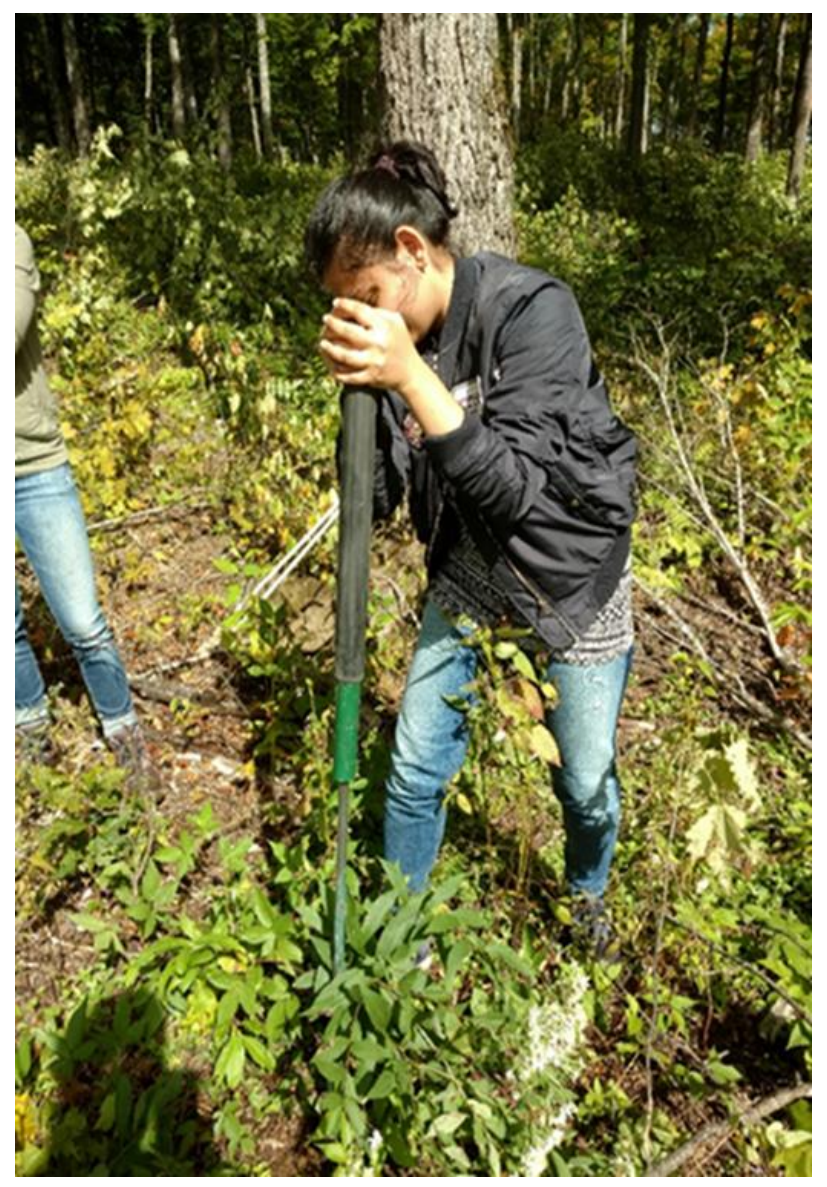

A

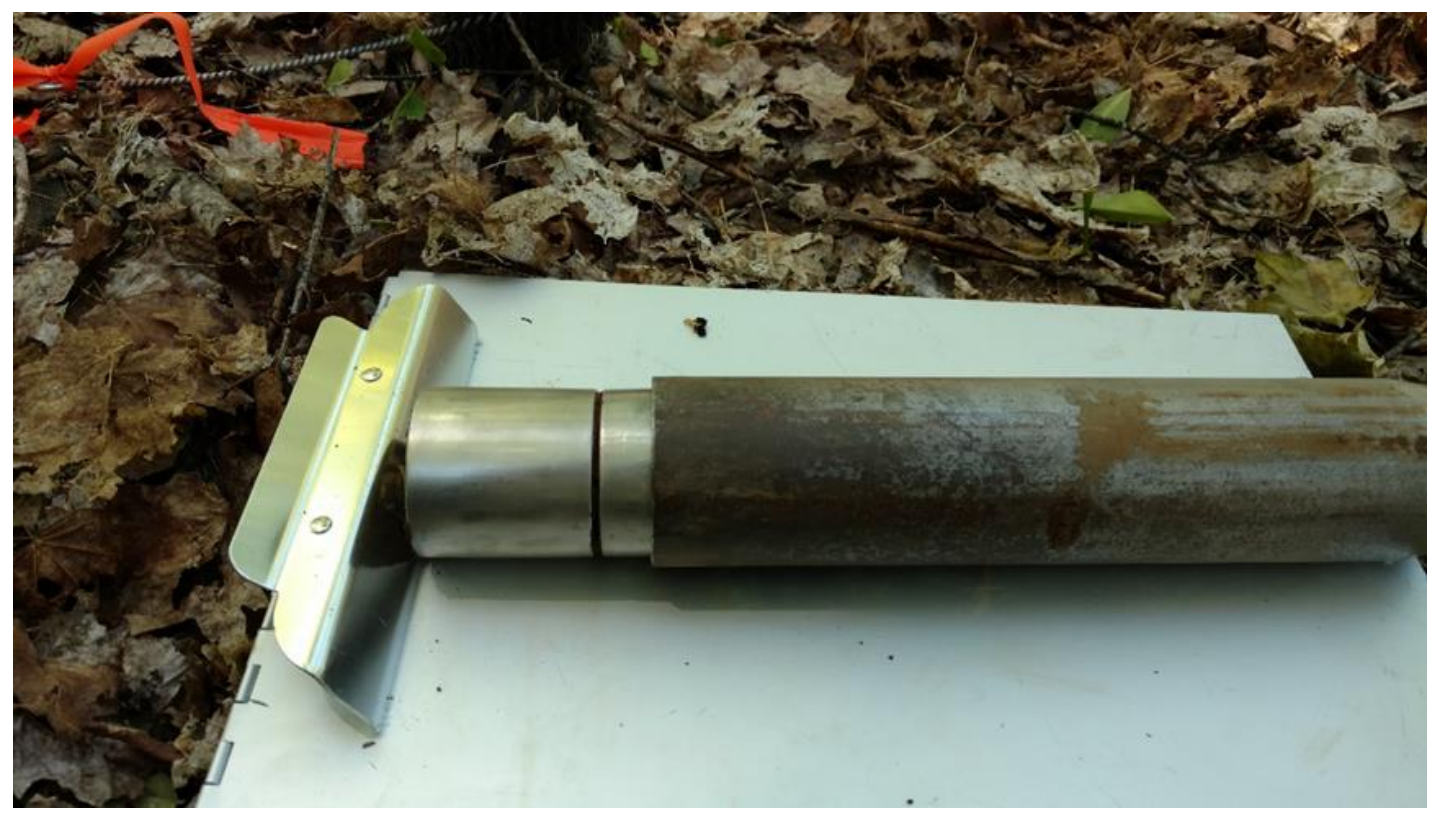

B 


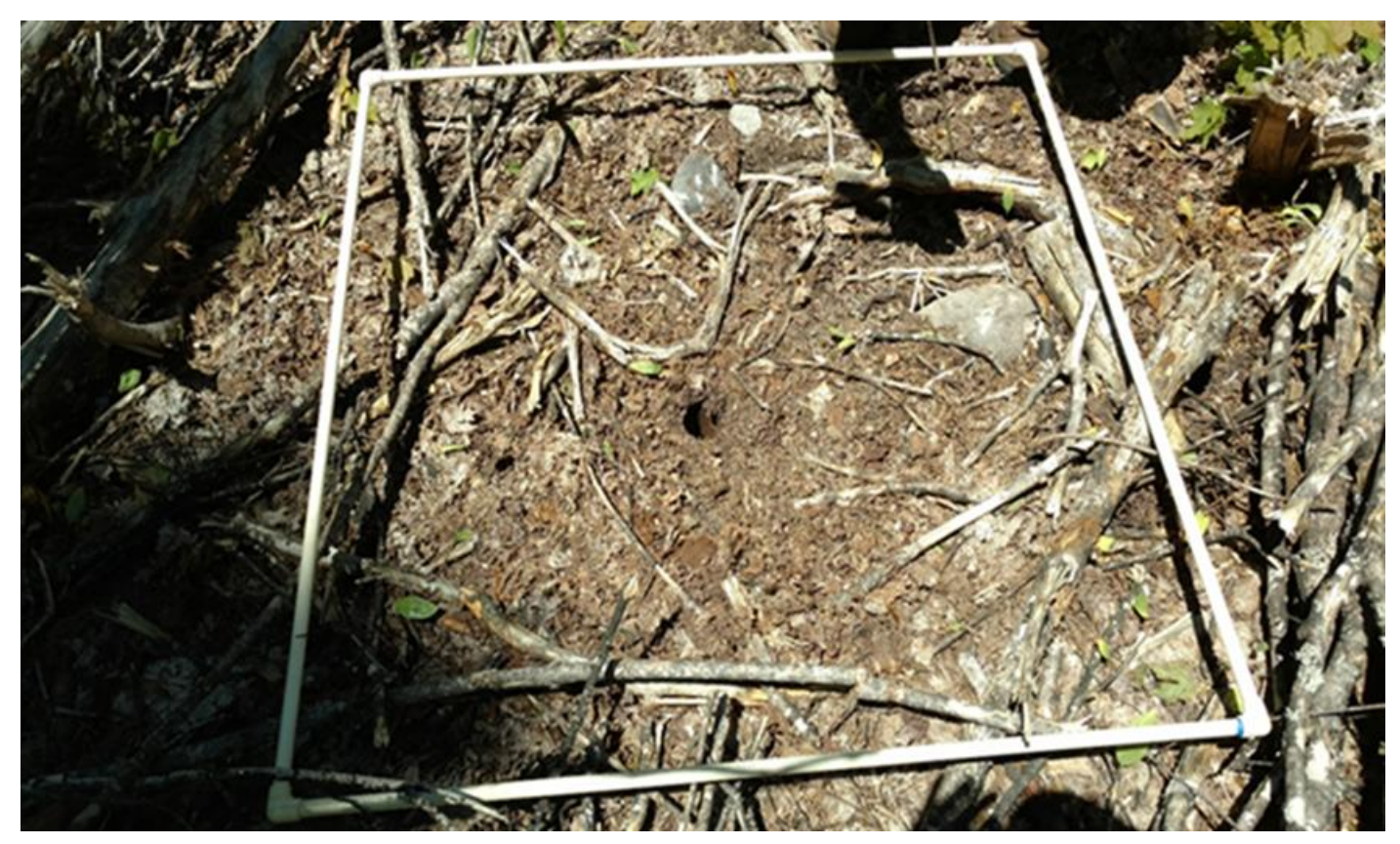

C

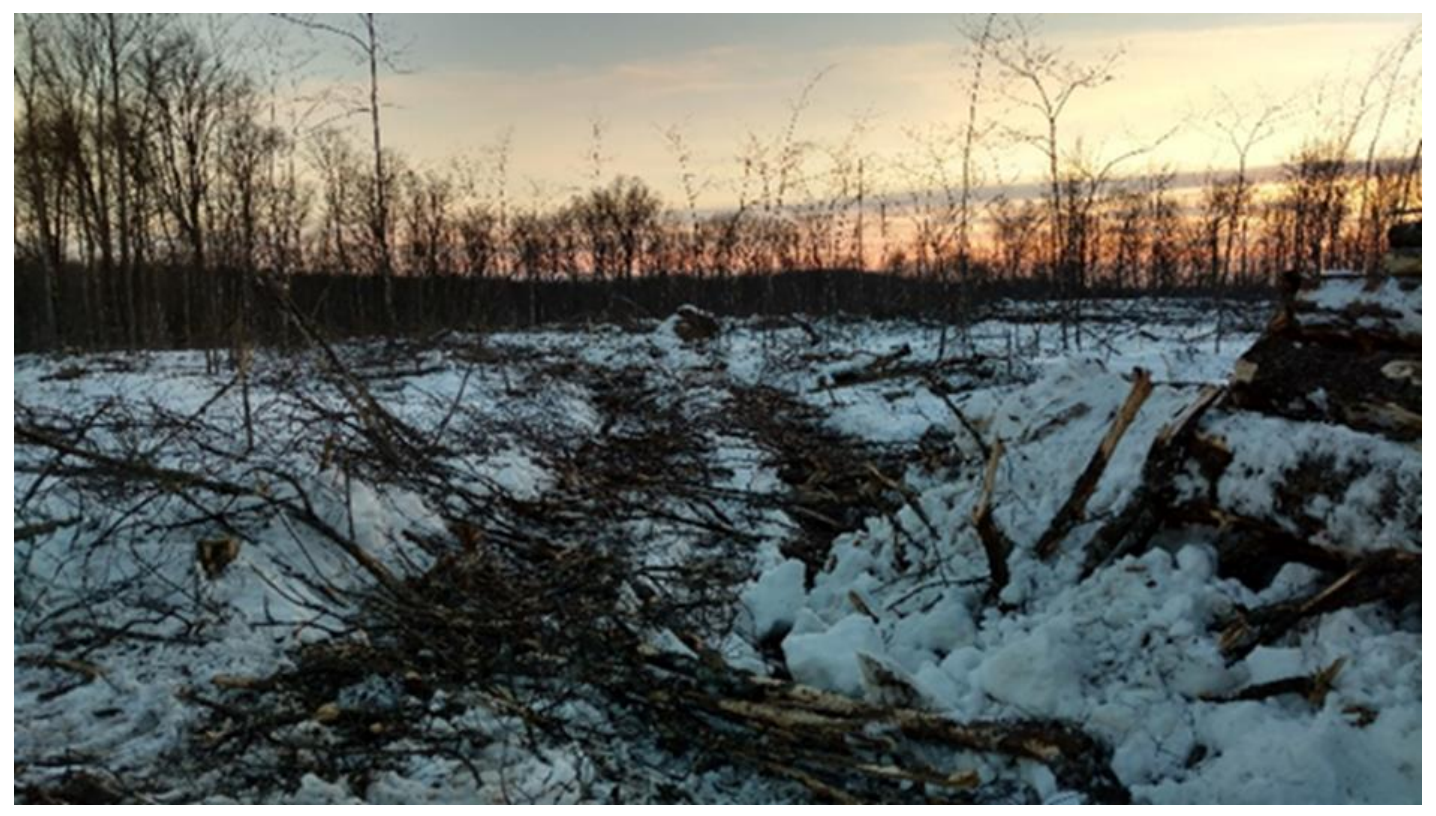

D 


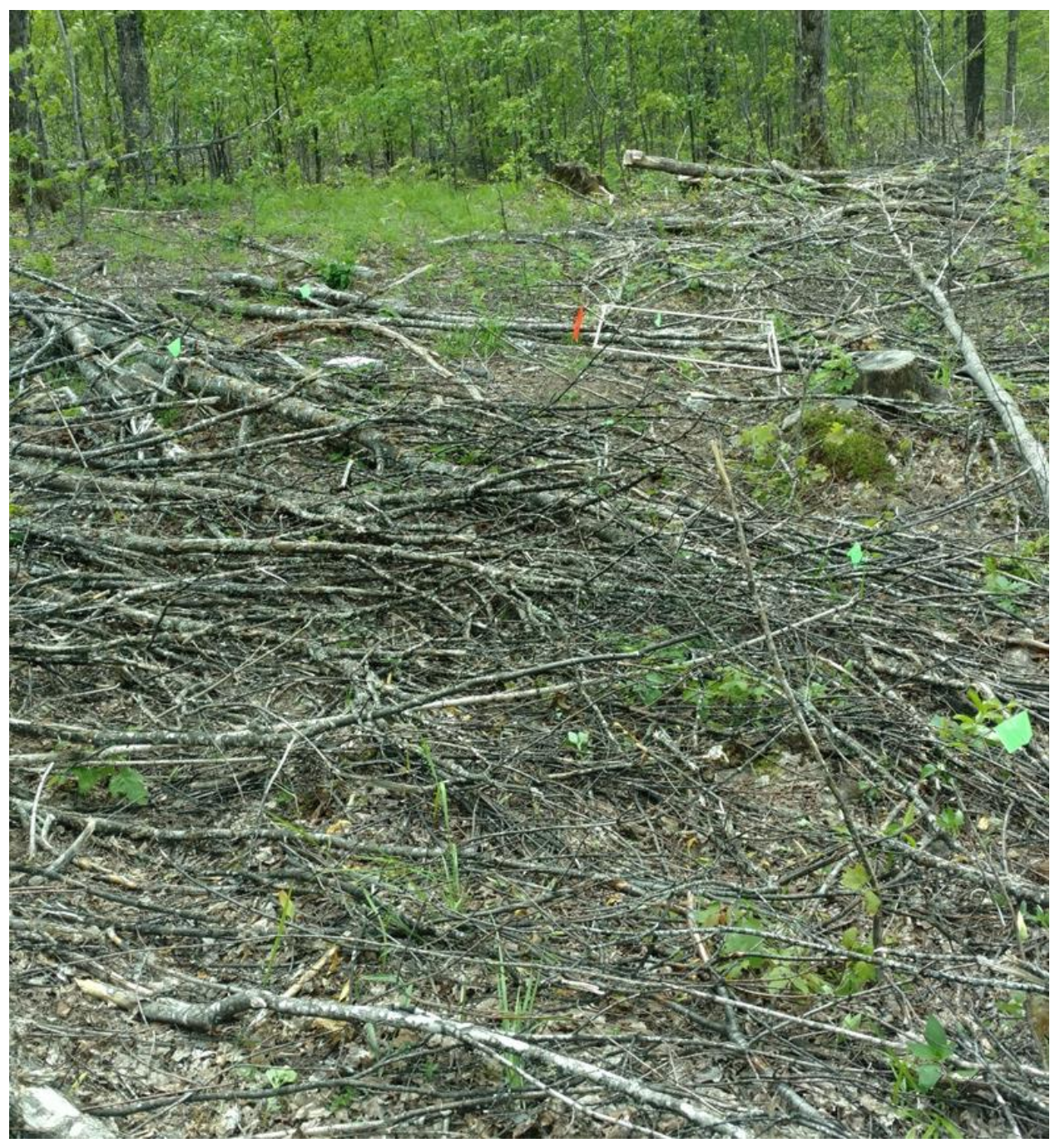

$\mathbf{E}$

Figure 11. A B showing soil samples were extracting using a slide hammer and a $20 \mathrm{~cm}$ corer. Samples were separated into different depths $(0-5,5-10,10-20 \mathrm{~cm})$ and C, D and E showing the skid trail, 12 sample points taken at 2 meters intervals along each side of the wheel tracks /ruts 


\subsection{Lab Procedures}

Bulk density $\left(\mathrm{g} / \mathrm{cm}^{3}\right)$ was measured for depths $0-5 \mathrm{~cm}, 5-10 \mathrm{~cm}$, and 10-20 $\mathrm{cm}$ for all samples. Soil samples were kept in a refrigerator in separate plastic bags maintaining a specific temperature after collecting the samples. An aluminum tray was used to weigh full soil samples with different depth and the measurement units were in grams.

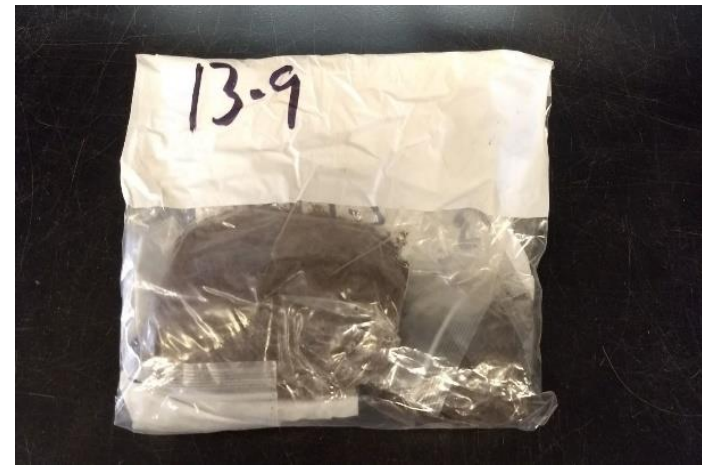

A

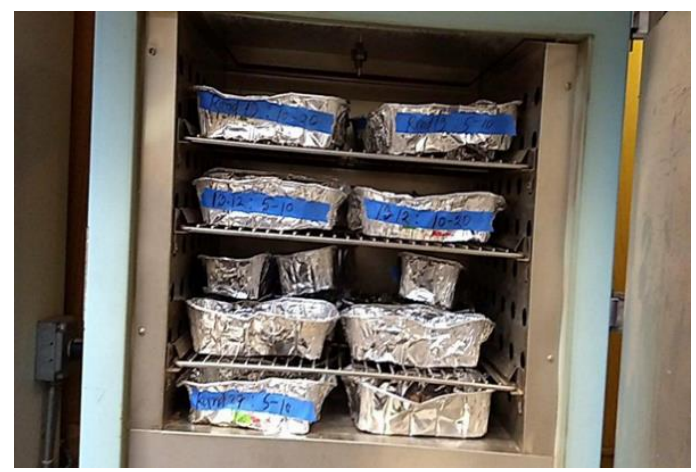

C

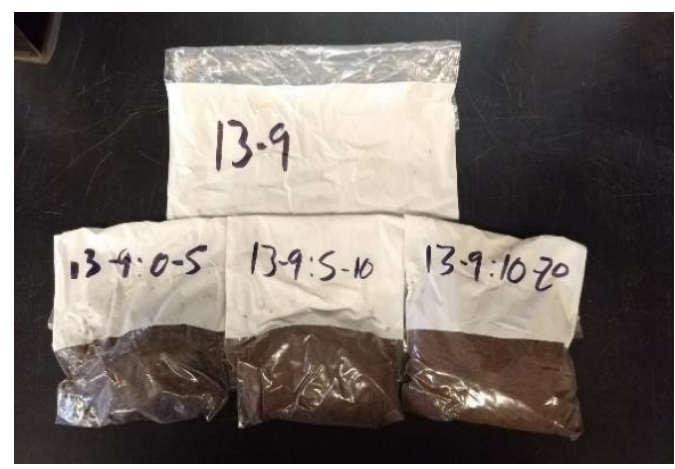

B

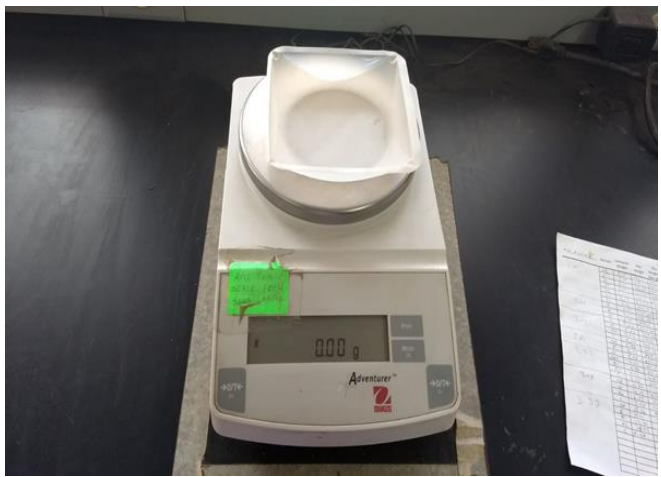

D

Fig 12. A and B (collected samples from research site with three subgroups according to depth $0-5$ $\mathrm{cm}, 5-10 \mathrm{~cm}$, and 10-20 cm), C (samples in the oven to remove the moisture content), D (scale for measuring the weight of soil for each depth) 
After weighing the full soil with moisture content, the specific temperature in the oven was maintained to remove the soil moisture content and that was 175-degree Fahrenheit and all the data were recorded. Then wooden rolling pin and spoon were used to grind the soil and using a sieve, the rocks were extracted from the sieve for different depth of soil samples. After this, rocks and fine soil were separated to weigh again and record the data. The weigh was taken for both rock and soil. Once drying, sifting, weighing were done all data were recorded again for bulk density calculation. The sieve size grade (\#10) was used in lab to separate fine soils from rocks and larger particles.

\subsection{Calculations}

Calculations were performed after collecting lab data to determine soil bulk density for fine sediment and the full soil sample. In addition, calculations were conducted to determine rock volume, percent rock content, and slash volume.

Volume calculations for cylinder liners:

- $\quad 10-20 \mathrm{~cm}$ liner: $\mathrm{h}=9.65 \mathrm{~cm}, \mathrm{r}=2.413 \mathrm{~cm}, \pi \mathrm{r}^{2} \mathrm{~h}=176.56 \mathrm{~cm}^{3}$

- $0-5$ and 5-10 cm liners: $\mathrm{h}=5.08 \mathrm{~cm}, \mathrm{r}=2.286 \mathrm{~cm}, \pi \mathrm{r}^{2} \mathrm{~h}=83.39 \mathrm{~cm}^{3}$

The volume of Soil $\left(\mathrm{cm}^{3}\right)$ :

- Volume of Cylinder - Volume of Rock (ml)

The volume of Rock $\left(\mathrm{cm}^{3}\right)$ :

- $\quad 0.2376+0.3962 *$ weight of Rock (Premer, 2016)

Percentage of Rock Volume (\%):

- Volume of rock/ (Volume of Soil + Volume of Rock)

Fine Soil Bulk Density $\left(\mathrm{g} / \mathrm{cm}^{3}\right)$ :

- Fine Soil Weight $(\mathrm{g}) /$ Volume of Soil $\left(\mathrm{cm}^{3}\right)$ 
Soil Bulk Density $\left(\mathrm{g} / \mathrm{cm}^{3}\right)$ :

- Weight of Dry Soil (g)/Volume of Cylinder $\left(\mathrm{cm}^{3}\right)$

Slash Volume $\left(\mathrm{kg} / \mathrm{m}^{3}\right)$ :

- $1 \mathrm{~m} \times 1 \mathrm{~m} \times$ Height of $\operatorname{slash}(\mathrm{m}) \times($ Packing Ratio/100)

\subsection{Data Analysis}

Data were analyzed using a mixed-effects model where the dependent variable (y) was soil bulk density, and independent fixed variables included machine traffic, slash volume, and overstory treatment, while percent rock content was included as a random variable. This model was fit for each depth of soil, and for total and fine soils. SAS version 9.4 was used to run the model. A separate regression analysis was run to estimate the effects of snow depth on bulk density.

Descriptive statistics were calculated using Microsoft excel to summarize the results. Additionally, one-way analysis of variance tests (ANOVA) was used to compare slash volume between partial and overstory treatments and to compare soil bulk density between 6 and 8-wheeled harvesters. 


\section{Results}

The primary objective of this research was to assess the effects of machine traffic, slash volume, percent rock content, overstory treatment and snow depth on soil bulk density. Data were collected from a total of 247 sample points across 18 plots (i.e. sections of skid trail) and 31 points that received no machine traffic.

\subsection{Summary Statistics}

According to Table 1 , the mean of fine soil bulk density was greater $\left(1.50 \mathrm{~g} / \mathrm{cm}^{3}\right)$ in $5-10$ $\mathrm{cm}$ depth than $0-5 \mathrm{~cm}\left(1.20 \mathrm{~g} / \mathrm{cm}^{3}\right)$ and $10-20 \mathrm{~cm}\left(1.44 \mathrm{~g} / \mathrm{cm}^{3}\right)$. Bulk densities for the full soil sample (including rock and cobble) were $1.12 \mathrm{~g} / \mathrm{cm}^{3}, 1.36 \mathrm{~g} / \mathrm{cm}^{3}$ and $1.28 \mathrm{~g} / \mathrm{cm}^{3}$ in $0-$ $5 \mathrm{~cm}, 5-10 \mathrm{~cm}$, and 10-20 cm soil depth, across all levels of machine traffic.

Variables related to rockiness such as attempts and average depth of failed attempts in each sample point, number of surface rocks, percent rock cover, and percent rock content in the soil were also measured in this study (Table 1$)$. The upper layer of soil $(0-5 \mathrm{~cm}$ depth), showed less rock content than soils at greater depths. The average percentage of rock volume in $0-5 \mathrm{~cm}$ was $6 \%$ compared with $10 \%$ in $5-10 \mathrm{~cm}$ and $10-20 \mathrm{~cm}$ soil depths. The range of percent surface rock cover varied from 0 to 26 . The results also showed that the mean number of surface rocks was 1.13 with a range of 0 to 15 . A number of sample points required multiple attempts to drive the cylinder in the ground to collect a soil sample due to the presence of rocks or other obstructions in the soil. The number of attempts and average depth of failed attempts were counted for each sample point. The range of number of attempts varied from 1 to 13 , with an average of 1.95 attempts per sample point. The 
depth at which a failed attempt was abandoned ranged from $1 \mathrm{~cm}$ to $19 \mathrm{~cm}$, with an average of $11.15 \mathrm{~cm}$.

Table 1. Descriptive Statistics for each variable showing the mean value

\begin{tabular}{|c|c|c|c|c|c|}
\hline Variable & Depth & Mean & $\begin{array}{l}\text { Standard } \\
\text { Deviation }\end{array}$ & Minimum & Maximum \\
\hline \multirow[t]{3}{*}{ Full Soil Bulk Density $(\mathrm{g} / \mathrm{cm} 3)$} & $0-5 \mathrm{~cm}$ & 1.12 & 0.21 & 0.47 & 1.75 \\
\hline & $5-10 \mathrm{~cm}$ & 1.36 & 0.24 & 0.75 & 2.09 \\
\hline & $10-20 \mathrm{~cm}$ & 1.28 & 0.21 & 0.40 & 1.81 \\
\hline \multirow[t]{3}{*}{ Fine Soil Bulk Density (g/cm3) } & $0-5 \mathrm{~cm}$ & 1.20 & 0.27 & 0.5 & 2.26 \\
\hline & $5-10 \mathrm{~cm}$ & 1.50 & 0.34 & 0.8 & 2.47 \\
\hline & $10-20 \mathrm{~cm}$ & 1.44 & 0.33 & 0.4 & 2.49 \\
\hline \multirow[t]{3}{*}{ Percentage of Rock volume } & $0-5 \mathrm{~cm}$ & 0.06 & 0.06 & 0.00 & 0.37 \\
\hline & $5-10 \mathrm{~cm}$ & 0.10 & 0.09 & -0.01 & 0.52 \\
\hline & $10-20 \mathrm{~cm}$ & 0.10 & 0.09 & 0.00 & 0.42 \\
\hline Attempts & & 1.95 & 1.69 & 1 & 13 \\
\hline Avg. Depth of Failed Attempts & & 11.15 & 5.20 & 1 & 19 \\
\hline \# of surface rocks & & 1.13 & 2.07 & 0 & 15 \\
\hline$\%$ rock cover & & 1.20 & 3.31 & 0 & 26 \\
\hline Average Snow Depth (inch) & & 10.50 & 5.19 & 1 & 19 \\
\hline Average slash volume $(\mathrm{kg} / \mathrm{m} 2)$ & & 0.0098 & 0.00 & 0.0 & 0.15 \\
\hline
\end{tabular}

\subsection{Effects of Overstory Treatments}

Results showed no significant difference between mean bulk density of soils under the two overstory treatments (clearcut and partial cut) on bulk density (Figure 13). The mean bulk densities were $1.22 \mathrm{~g} / \mathrm{cm} 3$ and $1.24 \mathrm{~g} / \mathrm{cm} 3$ for clearcut and partial cut harvest system in the 0-5 cm depth. It was $1.49 \mathrm{~g} / \mathrm{cm} 3$ and $1.52 \mathrm{~g} / \mathrm{cm} 3$ in $5-10 \mathrm{~cm}$ for clearcut and partial cut respectively. Only clearcut treatment plot showing a slightly higher mean bulk density $(1.54 \mathrm{~g} / \mathrm{cm} 3)$ than partial cut $(1.37 \mathrm{~g} / \mathrm{cm} 3)$ in $10-20 \mathrm{~cm}$ depth and interestingly no treatment samples showing slightly higher bulk density than partial cut. Data were also collected from no treatment area where the mean bulk densities were $1.02 \mathrm{~g} / \mathrm{cm} 3,1.47 \mathrm{~g} / \mathrm{cm} 3$ and $1.40 \mathrm{~g} / \mathrm{cm} 3$ in $0-5,5-10$ and $10-20 \mathrm{~cm}$ soil depth. 
Mean slash volumes were compared between the two silvicultural techniques used in this study (clearcut and partial cut) and no significant difference was detected (Appendix 17).

Figure 13. Showing the effect of overstory treatment on bulk density at three different soil depth

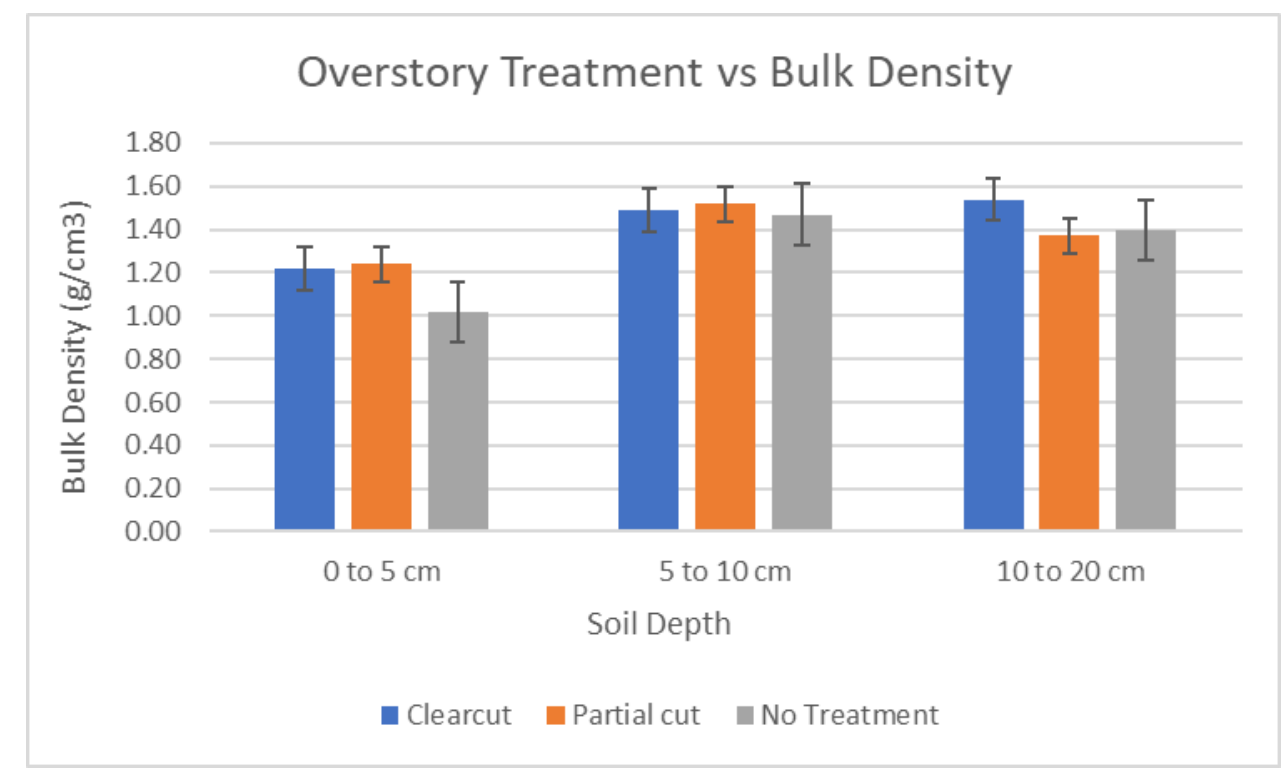

\subsection{Effect of 6-Wheeled vs 8-Wheeled Machines}

Both a six-wheeled harvester and eight-wheeled harvester were used during the harvest. The mean bulk densities for skid trails used by six-wheeled machine averaged over all levels of machine traffic were $1.20 \mathrm{~g} / \mathrm{cm} 3,1.48 \mathrm{~g} / \mathrm{cm} 3$, and $1.57 \mathrm{~g} / \mathrm{cm} 3$ for $0-5 \mathrm{~cm}, 5-10$ and 10-20 cm soil depths, respectively. The mean bulk densities for skid trails used by eight-wheeled machine averaged over all levels of machine traffic were $1.25 \mathrm{~g} / \mathrm{cm} 3,1.52$ $\mathrm{g} / \mathrm{cm} 3$, and $1.38 \mathrm{~g} / \mathrm{cm} 3$ for $0-5 \mathrm{~cm}, 5-10$, and $10-20 \mathrm{~cm}$ soil depths, respectively (Figure 14). One- way ANOVA analysis was conducted to test for differences in bulk density between the two machine types at each soil depth. The results showed that there was no significant effect was found on bulk density for 0-5 and 5-10 soil depth but at 10-20 cm 
depth there is significant difference due to six and eight-wheeled machines (Appendices 79).

Figure 14. Comparison of soil bulk densities for skid trails used by 8- and 6-wheeled harvesters

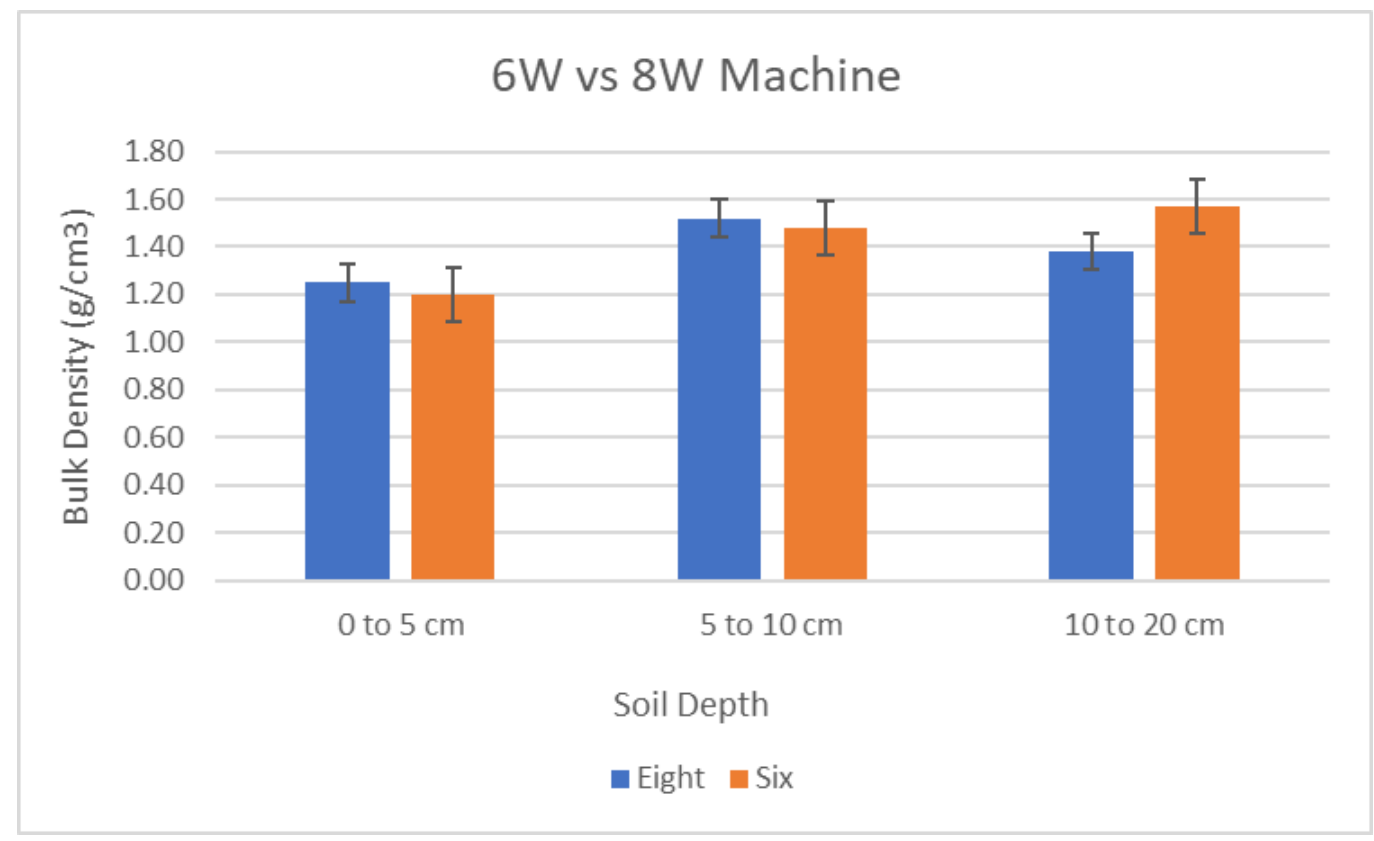

\subsection{Mixed Effects Model Results}

Mixed effects models were run for both full and fine soils, and at each depth (0-5, 5-10 and 10-20 $\mathrm{cm})$. Results show a significant effect of machine traffic and rock content for all models at the alpha $=0.05$ level except for the 5-10 full soil - the p-value for traffic for that model was 0.07 (Appendices 1-6).

\subsubsection{Effect of Traffic Intensity on Bulk Density}

The mean bulk densities were greater at the $5-10 \mathrm{~cm}$ depth compared to $0-5 \mathrm{~cm}$ where the means were $1.48 \mathrm{~g} / \mathrm{cm} 3,1.55 \mathrm{~g} / \mathrm{cm} 3,1.49 \mathrm{~g} / \mathrm{cm} 3$ and $1.48 \mathrm{~g} / \mathrm{cm} 3$ for low, medium, high and no traffic respectively. There was no significant difference between low and no traffic. Again, medium traffic intensity also showing the highest bulk density at $5-10 \mathrm{~cm}$ soil depth. At the $10-20 \mathrm{~cm}$ depth, the 
no traffic treatment was not significantly different than the low and high traffic treatment area but it was significantly different than the medium traffic treatments for $10-20 \mathrm{~cm}$ depth.

Mixed effects models were run in SAS to understand effects of various on bulk density for each depth of soil. Within SAS, PROC MIXED was used to fit a mixed model that included machine traffic, overstory treatment and slash volume as fixed effects and percent rock content as a random effect. Given that machine traffic was a significant factor in all but two model (5-10 fine and full soil). Bonferroni method was used to determine differences between pairs of machine traffic levels. For $0-5 \mathrm{~cm}$ depth, both fine soil and full soil resulted in significant differences in mean bulk density density between no traffic and both medium and high levels of machine traffic. In the $5-10 \mathrm{~cm}$ depth, differences in bulk density among traffic levels for full and fine soil were not significantly different at the $\alpha=.05$ level, though just barely (P-value $=0.06$ for both fine and full soils at 5-10 cm). On the other hand, there was a difference between high and low and low and medium traffic in the $10-20 \mathrm{~cm}$ depth. 
Figure 15. Relationship between bulk density and traffic intensity in three different depth $(0-5 \mathrm{~cm}$, $5-10 \mathrm{~cm}$ and $10-20 \mathrm{~cm}$ )

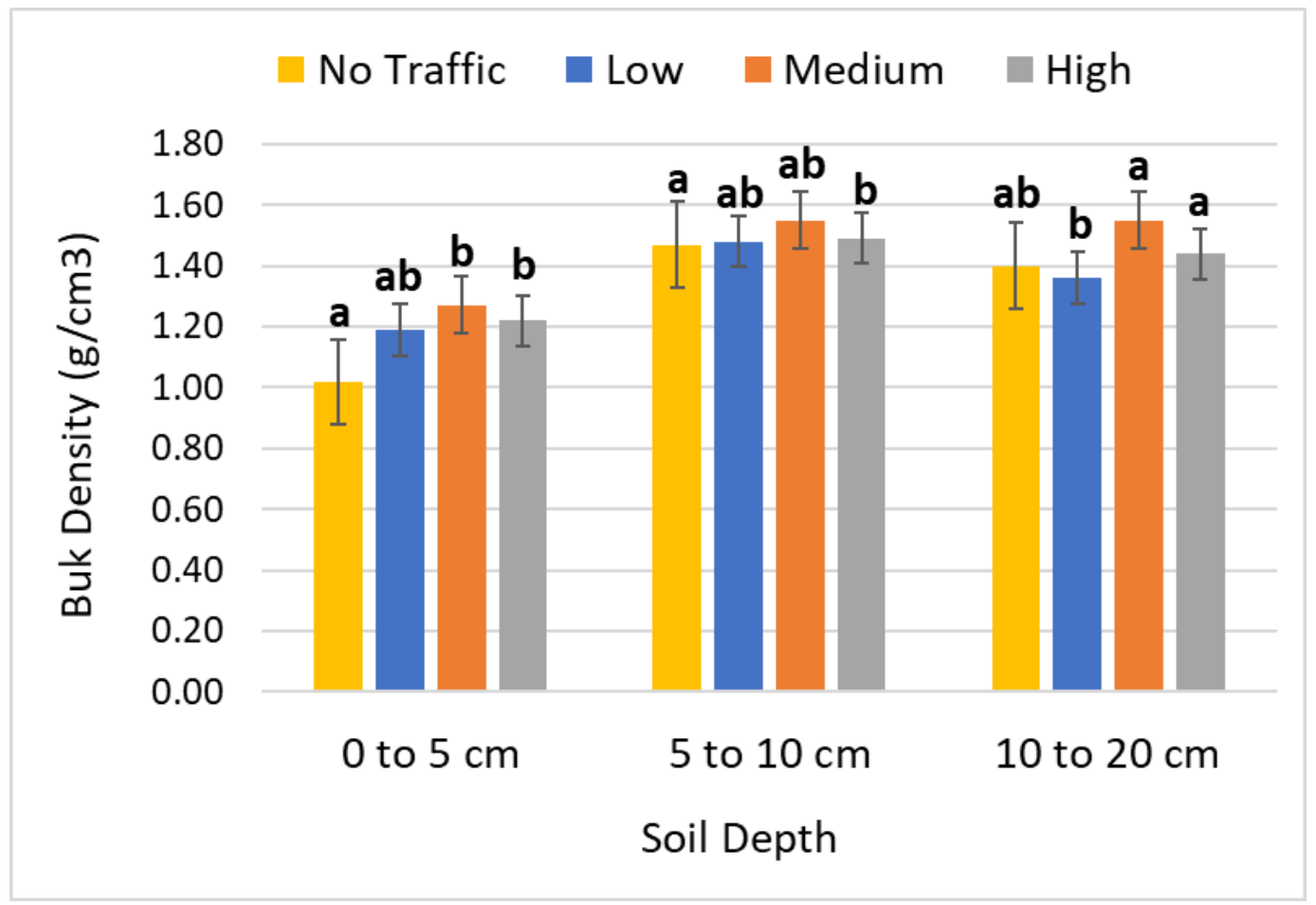

\subsubsection{Effect of Rock Content on Bulk Density}

To evaluate the effect of rock content on bulk density, an analysis was run in SAS using a mixed effects model where percent rock content was included as a random effect variable. The results show that rock content was a significant positive factor for predicting bulk density in this study. The effect of percent rock content was significant for 0-5 cm, 5-10 $\mathrm{cm}$ and 10-20 $\mathrm{cm}$ soil depth for both full and fine soil (Appendices 1-6).

\subsection{Effects of Snow Depth}

A simple linear regression was used to relate bulk density to snow depth in SAS using Proc GLM method. The results showed no significant relationship for the 0-5 and 5-10 cm depth for both full and fine soils also at 10-20 cm depth for full soil, but there was a significant 
effect at the 10-20 depth for fine soil. However, the effect was positive because bulk density increased as snow depth increased.

\section{0-20 Fine:}

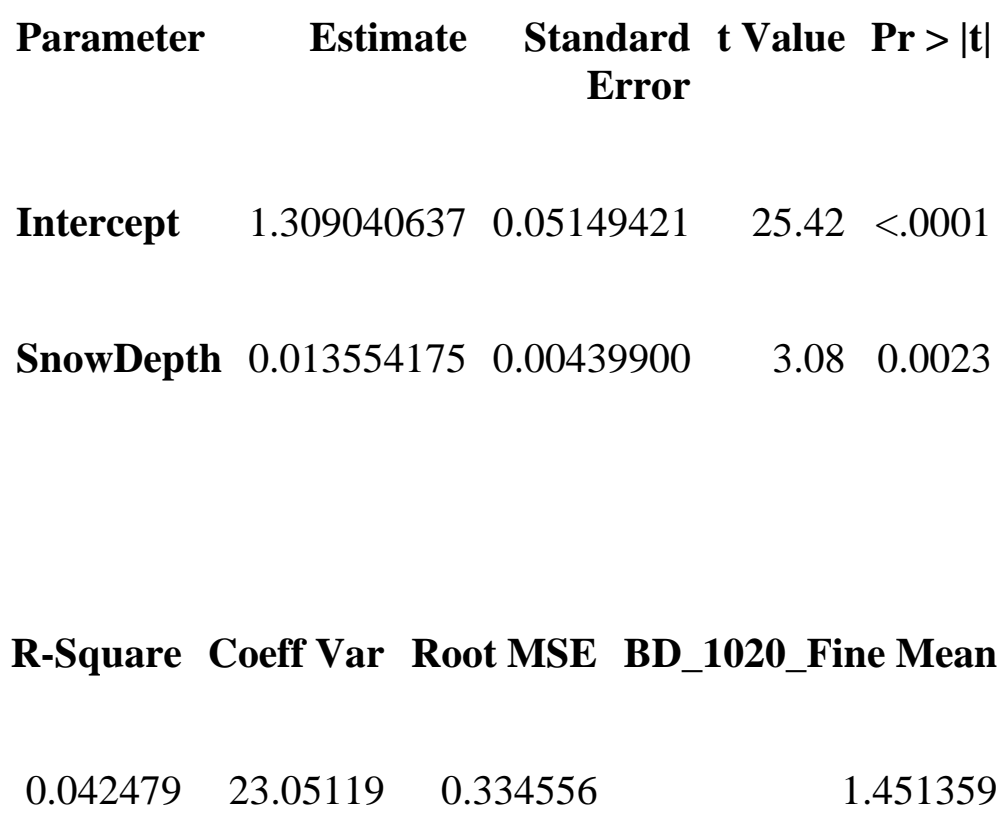




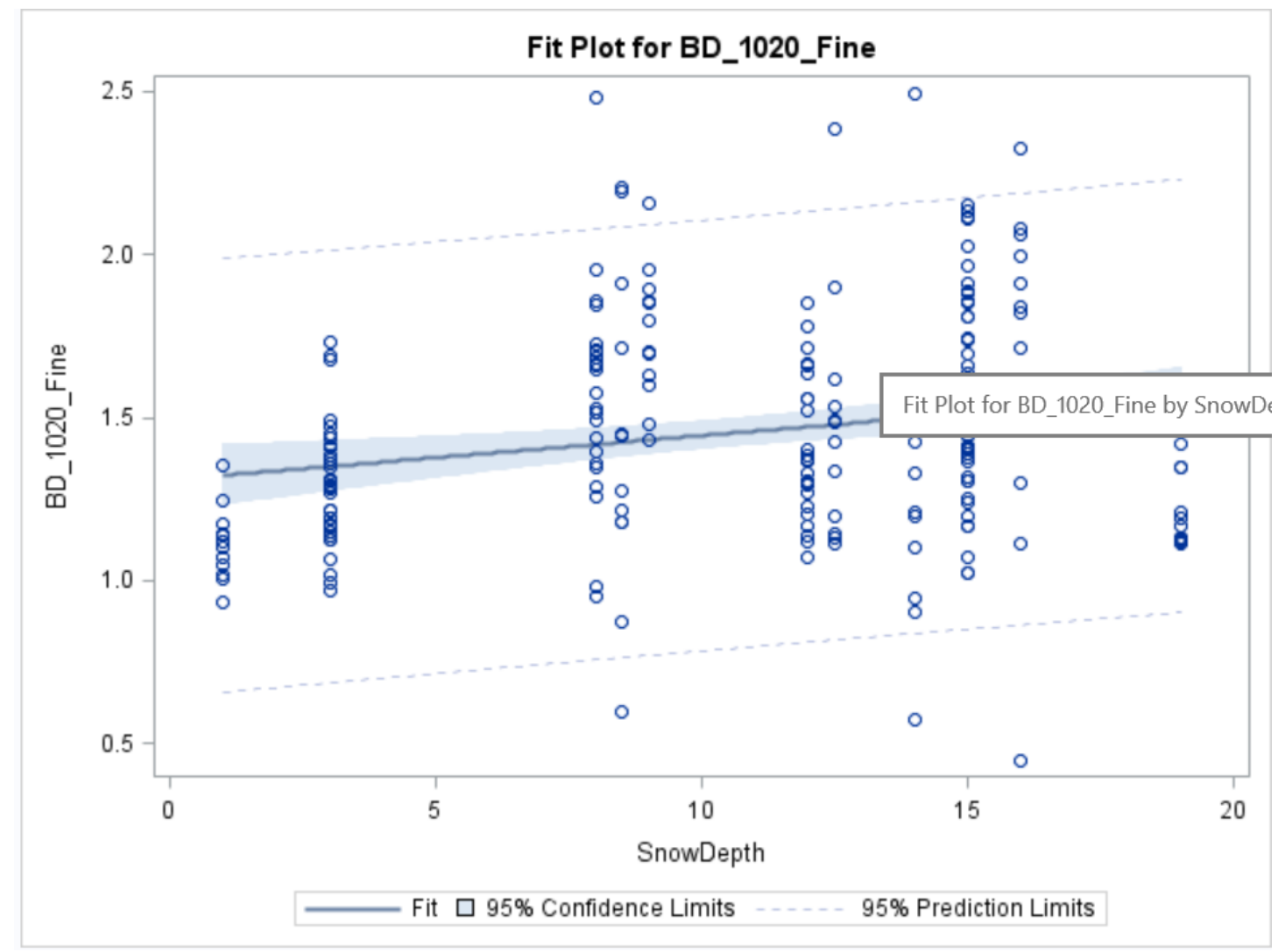

10-20 Full:

Parameter Estimate Standard $t$ Value $\operatorname{Pr}>|\mathbf{t}|$ Error

$\begin{array}{lllll}\text { Intercept } & 1.236833685 & 0.03257732 & 37.97 & <.0001\end{array}$

$\begin{array}{lllll}\text { SnowDepth } & 0.004387303 & 0.00278299 & 1.58 & 0.1164\end{array}$ 
R-Square Coeff Var Root MSE BD_1020_Full Mean
$0.011480 \quad 16.49804 \quad 0.211653$
1.282900

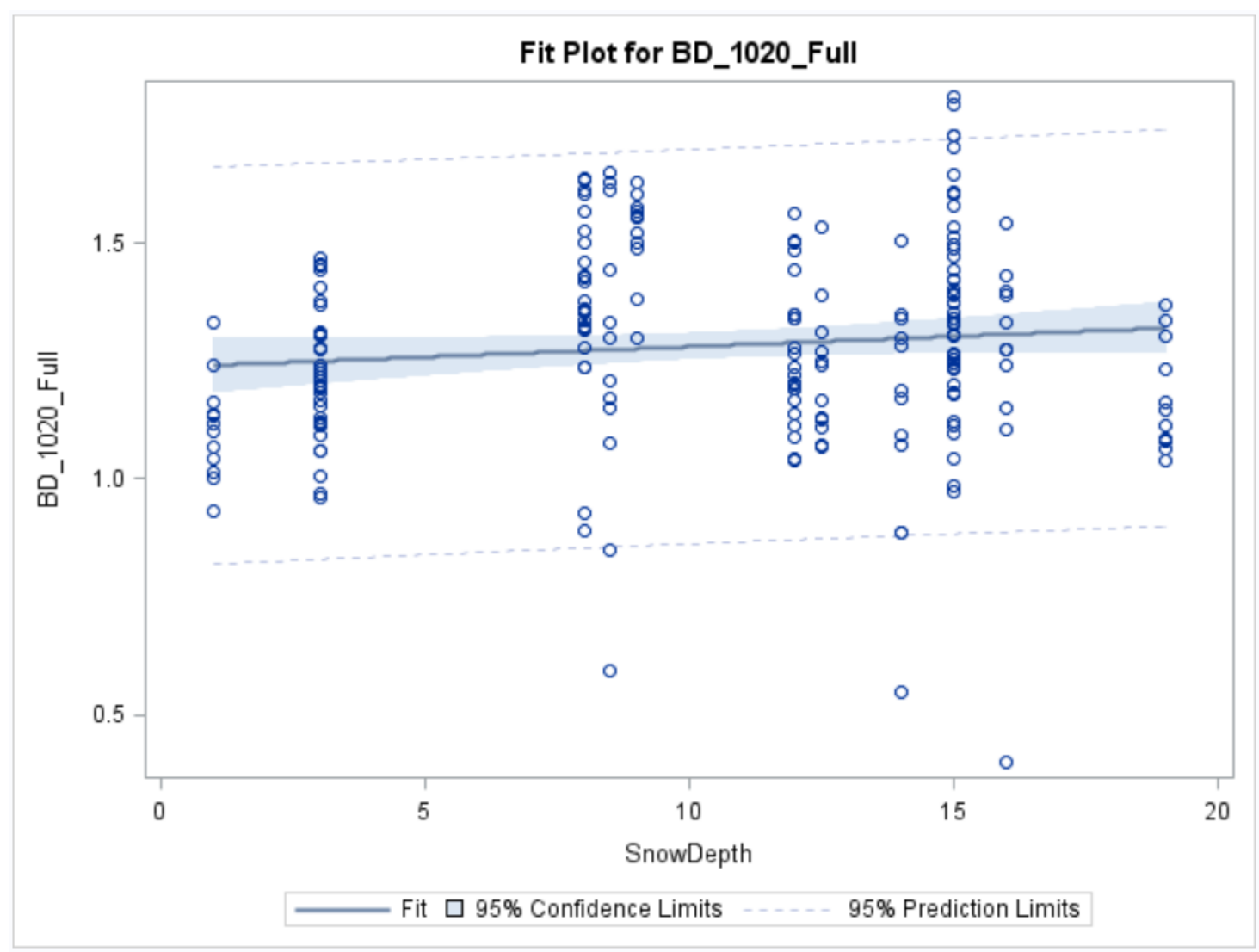




\section{Discussion}

\subsection{Effects of Traffic Intensity}

According to the results, mean bulk density within skid trails that experienced low machine traffic levels (1-3 passes) was not significantly greater than the mean bulk density for areas that experienced no traffic at the $0-5 \mathrm{~cm}$ depth. However, compared to the no traffic level, bulk density at the medium traffic level (5-7 passes) was $24 \%$ greater, and $17 \%$ greater for the high traffic level (>8 passes) for the full soil samples (including rock content) which were significant. This result suggests that compaction was significant in the upper layer of the soil once traffic exceeded 3 machine passes. At the $5-10 \mathrm{~cm}$ depth, significant differences in bulk density occurred between none and high level machine traffic, suggesting that compaction occurs after 7 machine passes at that depth for both full and fine soils. These results correspond with similar findings on the effects of machine traffic on soil bulk density, which are well-documented.

Jourgholami et al. (2014) observed that most of the changes in bulk density and total porosity happened after fewer than five passes, but significant changes of increases in penetration resistance occurred even after ten passes. On the other hand, Jansson and Johansson (1998) found at 40 to $50 \mathrm{~cm}$ depth of a silt loam soil, bulk density becomes higher with the increasing intensity of traffic (4-8 passes) and this happened for both a wheeled machine and a tracked machine. The tracked machine, in contrast, caused compaction at $5 \mathrm{~cm}$ depth. The maximum in comparison compaction (42\%) occurred at 10 cm depth following eight passes with the tracked machine, whereas with the wheeled machine maximum relative compaction (37\%) occurred at $15 \mathrm{~cm}$ depth after six passes. 
Agherkakli et al. (2010) proved that post-logging soil bulk densities were greatly higher than pre-logging bulk densities. They used two level of slopes (SC1, <20\% and SC2, > $20 \%$ ) and three levels of traffic intensity (one, five and nine traffics) for their study and observed the increment of bulk density in terms of percentage in SC1was 3\%, 6\% and $8 \%$ at the one, five and nine traffic frequency, respectively. In SC1 and SC2, the percentage of change in bulk density after the first traffic was $17.6 \%$ and $21 \%$, respectively. After first few machines passes the majority of compaction occurs, it becomes less in later on (Han et al., 2006; Wallbrink et al., 2002). Rab and Dignan (2002) reported that about 3\% more topsoil disturbance was related to 'wet season' logging.

In general, the effect of traffic intensity on soil bulk density decreases with increasing soil depth (Koolen et al., 1992) and with increasing number of passes, which is reflected in the results of this study. Williamson and Neilsen (2000) conducted a study of six clay to gravelly sandy soils and found that the uppermost $(10 \mathrm{~cm})$ portion of soil experienced $62 \%$ of soil compaction after a single machine pass, with little increase after following traffic. McNabb et al. (2001) showed that after three machine passes, the increasing rate of bulk densities were $10 \%, 7 \%$ and $4 \%$ at five, ten, and twenty $\mathrm{cm}$ soil depths respectively on a medium-textured soil. Other authors also recorded similar decreasing patterns at depths down to $30 \mathrm{~cm}$ (Han et al., 2009; Williamson and Neilsen, 2000). In the current study, bulk density increased significantly after three machine passes in the $0-5 \mathrm{~cm}$ depth and after 7 passes for the $5-10 \mathrm{~cm}$ depth.

According to the growth limiting bulk density textural triangle (Figure 2) (Daddow and Warrington, 1983), bulk density for a silt-loam soil occurs between 1.4 and $1.47 \mathrm{~g} / \mathrm{cm}^{3}$. In this study, we found that mean bulk densities at the $0-5 \mathrm{~cm}$ soil depth were not greater than 
$1.3 \mathrm{~g} / \mathrm{cm}^{3}$, which is lower than the threshold for root growth restriction. However, mean bulk density was highest for medium traffic intensity at $5-10 \mathrm{~cm}\left(1.55 \mathrm{~g} / \mathrm{cm}^{3}\right)$ and $10-20$ $\mathrm{cm}\left(1.55 \mathrm{~cm}^{3}\right)$ soil depth which could limit tree growth.

\subsection{Effects of Slash Volume}

There was no significant effect of slash volume on bulk density, according to the data collected in this study. However, McDonald and Seixas (1997) conducted a study where two levels of traffic, three slash densities and two soil moisture contents were measured to quantify soil compaction. They found soil compaction did not reduce after one forwarder pass on dry, loamy sand soils due to slash, but it was noticed for additional passes, where slash did provide some protection. Results from that study indicated that slash cover is mostly beneficial on wet soils. However, another previous study was conducted to identify the effect of machine passes, soil moisture, and slash on penetration resistance in a fine loamy to loam soil using a cut-to-length harvest system (Han et al. 2006). The authors found that slash does not have any significant effects with an increasing number of machine passes and suggested that moist soil may require a high amount of slash to protect it from long term negative impacts of soil compaction. Slash may also it possibly help to reduce ruts as well (Han et al. 2006). Similarly, no effect of slash volume on bulk density was detected for the current study at 0-5, 5-10 and 10-20 cm soil depth.

Hutchings et al. (2002) reported that soil compaction occurs with normal harvesting operations. In that study, they suggested creating slash mat rather than working on bare soil in a clay loam soil in order to decrease compaction. Another report showed that compaction was reduced by $12.9 \%$ at a $10 \mathrm{~cm}$ soil depth and by $4.5 \%$ at $20 \mathrm{~cm}$ in a silty clay soil after generating a $10 \mathrm{~cm}$ thick slash mat on strip roads (Eliasson and Wästerlund, 
2007). In another study, Han et al. (2009) investigated soil compaction on an Andisol soil in a mixed coniferous forest using a cut-to-length and whole-tree harvesting system. Avoiding the negative effect on soil compaction, they suggested leaving an amount of 7$40 \mathrm{~kg} / \mathrm{m}^{2}$ of slash on the ground. Labelle and Jaeger (2012) also recommended leaving as a minimum of $15-20 \mathrm{~kg} / \mathrm{m}^{2}$ of slash over highly vulnerable soils and concluded that, although slash mats lose a small amount of capability to distribute the applied loads with increasing machine passes, they are still useful at high traffic frequencies, for example, 12 forwarder cycles. Leaving slash on the ground is hence a useful practice to reduce soil compaction, However, Eliasson and Wästerlund (2007) did not find any major decrease of rut depth after one, two and five machine passes on top of a 10-20 cm thick slash mat in a silty clay forest soil in Sweden.

Akay et al. (2007) suggest that woody material other than slash, such as chip and sawdust also help to decrease soil compaction. It was not suggested to remove slash cover completely if soil needs protection from post-harvesting erosion (Rice and Datzman, 1981; Edeso et al., 1999). Parkhurst et al. (2018) reported that providing slash cover had limited effect on changes in bulk density and porosity than using the forest floor for overland skidding. In our study, though clearcut and partial cut were applied as two overstory treatments to notice if there is any significant effect of slash volume on soil compaction, we did not find any significant effect of slash on soil bulk density. As we know that slash continues to breakdown over time, it can assume that slash will add more organic matter to the ground of this research site and help to regenerate trees also add benefits to some habitat of micro-organism community as well. 


\subsection{Effects of Percent Rock Content}

Houston and Walsh (1993) investigated the differences in rock correction methods designed for compaction of clayey soils in laboratory. They observed very significant differences in maximum dry density using scalp-and-replace procedures compared with the rock correction equations when soil fines are clay. Rücknagel et al. (2013) reported fine earth (A soil which can be passed through a 2-millimeter sieve without grinding its primary particles) in gravelly soils is less vulnerable to compaction. They also observed that a maximum gravel content of around $25 \%$ by volume, fine earth bulk density remained nearly constant although the total bulk density of the soil gradually increased.

\subsection{Winter Harvesting BMPs}

The uniqueness of this study is that, although harvesting is generally preferred and recommended in northern hardwood stands in the Western UP, there has been little research on the effects of harvesting in the winter on soil compaction in this region. However, in light of the findings that medium and high levels of machine traffic resulted in higher bulk densities in this study, winter harvests can still impact soils. It is possible that winter harvesting resulted in less impacts on soils (compaction, rutting, disturbance) than summer harvesting. However, we do not have data with which to compare the effects of season, as we did not collect data of summer harvesting from our study site, or a similar site. Zasada et al. (1987) showed that winter logging is may be preferred to summer because of easier access to different surfaces of floodplains as river and poorly drained areas become frozen. They also observed that tree regeneration can be protected from physical injury by logging with a good snowpack. 
Stone (2002) conducted an experiment that examines the effects of winter logging on soil disturbance and regeneration in Western Upper Michigan and reported that drier soil conditions can minimalize soil compaction and rutting. Stone (2002) also suggested that plowing snow from skid trails might be a solution that will permit the soil to freeze and improve compaction and rutting and the time of plowing and cost also could be economically advantageous to save equipment maintenance and fuel costs. That might not be practical as the forest floor has many obstacles, such as stumps, rocks and uneven terrain that would make plowing skid trails difficult (unlike plowing roads which are flat and generally free of any stumps or other obstructions). Not only that, removing snow from the skid trail can also cause disturbance to soil nutrients during plowing as the uppermost soil layer becomes disturbed with the blade of the snowplow.

\subsection{Limitations and Future Research}

Though we did not find any effect of snow depth on bulk density at 0-5 cm and 5-10 cm soil depth but our data showed that there is significant effect at 10-20. It was expected that greater snow depth would protect soils, leading to lower bulk density. However, this study did not control for snow depth, and thus snow depth for the randomly selected plots seemed to cluster around 15 inches, with little variability. In addition, soil moisture content was measured periodically from non-skid trail areas during the harvest, resulting in a range of roughly 35 to $50 \%$ moisture content, however soil moisture content was not measured from sampling plots at the time those segments of skid trail were traversed by the logging machines. For this reason, moisture content data were not included in this study. However, previous research has shown that soil moisture content can be a significant factor affecting soil compaction during harvest operations. Finally, although the higher bulk densities 
found in the 5-10 cm appear to exceed the threshold at which root growth could be limited, future research is needed to further determine if the compaction observed in these skid trails has any significant effect on tree growth. Thus, it is recommended that future research look at measuring the growth rate of trees from both high and low traffic areas of this study site. 


\section{Conclusion}

This study assessed the effects of percent rock content, slash volume, traffic intensity, overstory treatment and snow depth on bulk density in Ford Forest, Alberta, Michigan.

Four levels of traffic intensities (none, low, medium, high) and two levels of overstory treatments (partial and clearcut) were used to assess the effects where the dependent variable was bulk density, fixed variables were slash volume, traffic intensity and random variable was percent rock content. Separate linear regressions were also run to calculate the effect of snow depth on bulk density at each depth $(0-5,5-10,10-20 \mathrm{~cm})$.

For 0-5 cm depth, mean soil bulk density for both medium and high levels of machine traffic were significantly greater than the mean bulk density of soils from areas that experienced no machine traffic. However, no significant difference was detected between low traffic and no traffic. Thus, at the $0-5 \mathrm{~cm}$ depth, more than three passes can cause increased compaction, however this compaction may not be enough to limit root growth. There was a difference between high-low and low-medium traffic in 10-20 cm depth, suggesting that passes over 7 can result in higher compaction at this depth. The percent rock content has a positive significant effect on bulk density, but no effect was detected for slash volume and snow depth, except at the 10-20 cm depth where snow depth seems to have some effect.

From this study the suggestion for foresters and loggers is, 1) though winter harvesting is generally preferred in order to protect soils, managers still need to be aware of potential impacts to soil for main skid trails that receive higher levels of traffic, 2) although no effect of slash volume on mitigating compaction was detected, it is still recommended to place slash on skid trails during harvest operation due to the benefits of slash reported from 
previous studies, and 3) more research is needed for effects of snow as we noticed counterintuitive result at $10-20 \mathrm{~cm}$ but not at $0-5$ and $5-10 \mathrm{~cm}$ depth. At $10-20 \mathrm{~cm}$ depth, data showed a significant positive relationship between snow depth and bulk density only for fine soil. 


\section{References}

"National Oceanic and Atmospheric Administration". Data accessed from https://www.ncdc.noaa.gov/cdo-web/datatools/normals on 30 September, 2019.

"Natural Resources Conservation Service, United States Department of Agriculture". Data accessed from https://websoilsurvey.sc.egov.usda.gov/App/WebSoilSurvey.aspx on 30 September, 2019.

"Natural Resources Conservation Service, United States Department of Agriculture". Document accessed from https://www.nrcs.usda.gov/Internet/FSE_DOCUMENTS/nrcs142p2_053260.pdf on 1 October, 2019.

Agherkakli, B., Najafi, A. and Sadeghi, S.H. 2010. Ground based operation effects on soil disturbance by steel tracked skidder in a steep slope of forest. Journal of forest science, 56(6), pp.278-284.

Akay, A. and Sessions, J. 2001. Minimizing road construction plus forwarding costs under a maximum soil disturbance constraint. In The International Mountain Logging and 11th Pacific Northwest Skyline Symposium, December (pp. 10-12).

Akay, A.E., Yuksel, A., Reis, M. and Tutus, A. 2007. The impacts of ground-based logging equipment on forest soil. Polish Journal of Environmental Studies, 16(3), p.371.

Ballard, T.M. 2000. Impacts of forest management on northern forest soils. Forest ecology and management, 133(1-2), pp.37-42.

Bates, P.C., Blinn, C.R. and Alm, A.A. 1993. Harvesting impacts on quaking aspen regeneration in northern Minnesota. Canadian Journal of Forest Research, 23(11), pp.2403-2412.

Bigelow, S.W., Jansen, N.A., Jack, S.B. and Staudhammer, C.L. 2018. Influence of Selection Method on Skidder-Trail Soil Compaction in Longleaf Pine Forest. Forest Science, 64(6), pp.641-652.

Bodelier, P., Libochant, J.A., Blom, C.W.P.M. and Laanbroek, H.J. 1996. Dynamics of nitrification and denitrification in root-oxygenated sediments and adaptation of ammoniaoxidizing bacteria to low-oxygen or anoxic habitats. Appl. Environ. Microbiol., 62(11), pp.4100-4107. 
Brais, S. and Camire, C. 1998. Soil compaction induced by careful logging in the claybelt region of northwestern Quebec (Canada). Canadian Journal of Soil Science, 78(1), pp.197206.

Cambi, M., Certini, G., Neri, F. and Marchi, E. 2015. The impact of heavy traffic on forest soils: A review. Forest ecology and management, 338, pp.124-138.

Carter, E.A., McDonald, T.P. and Torbert, J.L. 1999. Application of GPS technology to monitor traffic intensity and soil impacts in a forest harvest operation. In Paper presented at the Tenth Biennial Southern Silvicultural Research Conference, Shreveport, LA, February 16-18, 1999.

Coder, K. D. 2000. Defining Soil Compaction: Sites \& Trees. Available from https://www.extension.iastate.edu/forestry/publications/PDF_files/for00-004.pdf

[Accessed 14 January, 2019]

Daddow, R.L. and Warrington, G. 1983. Growth-limiting soil bulk densities as influenced by soil texture. Watershed Systems Development Group, USDA Forest Service.Hillel, D. 1998. Environmental soil physics: Fundamentals, applications, and environmental considerations. Elsevier.

Daddow, R.L. and Warrington, G. 1983. Growth-limiting soil bulk densities as influenced by soil texture. Watershed Systems Development Group, USDA Forest Service.

DeJong-Hughes, J. 2018. Soil compaction. Available from https://extension.umn.edu/soilmanagement-and-health/soil-compaction [accessed 22 January, 2018]

Demir, M., Makineci, E. and Yilmaz, E. 2007. Investigation of timber harvesting impacts on herbaceous cover, forest floor and surface soil properties on skid road in an oak (Quercus petrea L.) stand. Building and Environment, 42(3), pp.1194-1199.

Dominati, E., Patterson, M. and Mackay, A. 2010. A framework for classifying and quantifying the natural capital and ecosystem services of soils. Ecological Economics, 69(9), pp.1858-1868.

Edeso, J.M., Merino, A., Gonzalez, M.J. and Marauri, P. 1999. Soil erosion under different harvesting managements in steep forestlands from northern Spain. Land Degradation \& Development, 10(1), pp.79-88.

Eisenbies, M.H., Burger, J.A., Aust, W.M. and Patterson, S.C. 2005. Soil physical disturbance and logging residue effects on changes in soil productivity in five-year-old pine plantations. Soil Science Society of America Journal, 69(6), pp.1833-1843. 
Eliasson, L. and Wästerlund, I. 2007. Effects of slash reinforcement of strip roads on rutting and soil compaction on a moist fine-grained soil. Forest Ecology and Management, 252(13), pp.118-123.

Elliot, W.J., Page-Dumroese, D. and Robichaud, P.R. 1998. 12 The Effects of Forest Management on Erosion and Soil Productivity. Soil quality and soil erosion, p.195.

Frey, B., Kremer, J., Rüdt, A., Sciacca, S., Matthies, D. and Lüscher, P. 2009. Compaction of forest soils with heavy logging machinery affects soil bacterial community structure. European Journal of Soil Biology, 45(4), pp.312-320.

Froehlich, H.A., Miles, D.W.R. and Robbins, R.W. 1985. Soil Bulk Density Recovery on Compacted Skid Trails in Central Idaho 1. Soil Science Society of America Journal, 49(4), pp.1015-1017.

Greacen, E.L. and Sands, R. 1980. Compaction of forest soils. A review. Soil Research, 18(2), pp.163-189.

Greene, W.D., Marchman, S.C. and Baker, S.A. 2013, July. Changes in logging firm demographics and logging capacity in the US South. In Proceedings of the 36th Annual Council on Forest Engineering Meeting (p. 7).

Grigal, D.F. 2000. Effects of extensive forest management on soil productivity. Forest Ecology and Management, 138(1-3), pp.167-185.

Håkansson, I. and Reeder, R.C. 1994. Subsoil compaction by vehicles with high axle load - extent, persistence and crop response. Soil and Tillage Research, 29(2-3), pp.277304.

Hammond, H.L. 1978. Skid road layout study, 1977. Nelson Forest District. Unpublished preliminary report submitted to the British Columbia Forest Service, Nelson, B.C., 25 April 1978.

Han, H.S., Page-Dumroese, D., Han, S.K. and Tirocke, J. 2006. Effects of slash, machine passes, and soil moisture on penetration resistance in a cut-to-length harvesting. International journal of forest engineering, 17(2), pp.11-24.

Han, S.K., Han, H.S., Page-Dumroese, D.S. and Johnson, L.R. 2009. Soil compaction associated with cut-to-length and whole-tree harvesting of a coniferous forest. Canadian Journal of Forest Research, 39(5), pp.976-989. 
Hatchell, G.E., Ralston, C.W. and Foil, R.R. 1970. Soil disturbances in logging: Effects on soil characteristics and growth of loblolly pine in the Atlantic Coastal Plain. Journal of Forestry, 68(12), pp.772-5.

Horn, R., Vossbrink, J. and Becker, S. 2004. Modern forestry vehicles and their impacts on soil physical properties. Soil and Tillage Research, 79(2), pp.207-219.

Houston, S.L. and Walsh, K.D. 1993. Comparison of rock correction methods for compaction of clayey soils. Journal of geotechnical engineering, 119(4), pp.763-778.

Hutchings, T.R., Moffat, A.J. and French, C.J. 2002. Soil compaction under timber harvesting machinery: a preliminary report on the role of brash mats in its prevention. Soil use and Management, 18(1), pp.34-38.

Jamshidi, R., Jaeger, D., Raafatnia, N. and Tabari, M. 2008. Influence of two ground-based skidding systems on soil compaction under different slope and gradient conditions. International journal of forest engineering, 19(1), pp.9-16.

Jansson, K.J. and Johansson, J., 1998. Soil changes after traffic with a tracked and a wheeled forest machine: a case study on a silt loam in Sweden. Forestry: An International Journal of Forest Research, 71(1), pp.57-66.

Jourgholami, M., Soltanpour, S., Etehadi Abari, M. and Zenner, E.K. 2014. Influence of slope on physical soil disturbance due to farm tractor forwarding in a Hyrcanian forest of northern Iran. iForest-Biogeosciences and Forestry, 7(5), p.342.

Koolen, A.J., Lerink, P., Kurstjens, D.A.G., Van den Akker, J.J.H. and Arts, W.B.M. 1992. Prediction of aspects of soil-wheel systems. Soil and Tillage research, 24(4), pp.381-396.

Kozlowski, T.T. 1999. Soil compaction and growth of woody plants. Scandinavian Journal of Forest Research, 14(6), pp.596-619.

Krag, R., Higginbotham, K. and Rothwell, R. 1986. Logging and soil disturbance in southeast British Columbia. Canadian Journal of Forest Research, 16(6), pp.1345-1354.

Labelle, E.R. and Jaeger, D. 2012. Quantifying the use of brush mats in reducing forwarder peak loads and surface contact pressures. Croatian Journal of Forest Engineering: Journal for Theory and Application of Forestry Engineering, 33(2), pp.249-274.

Laffan, M., Jordan, G. and Duhig, N. 2001. Impacts on soils from cable-logging steep slopes in northeastern Tasmania, Australia. Forest Ecology and Management, 144(1-3), pp.91-99. 
Malo, C. and Messier, C. 2011. Impact of primary and secondary machinery tracks on fine root growth of sugar maple after selection cutting. Canadian journal of forest research, 41(4), pp.892-897.

Martin, C.W. 1988. Soil disturbance by logging in New England review and management recommendations. Northern Journal of Applied Forestry, 5(1), pp.30-34.

McDonald, T.P. and Seixas, F. 1997. Effect of slash on forwarder soil compaction. Journal of forest engineering, 8(2), pp.15-26.

McDonald, T.P., Carter, E.A. and Taylor, S.E. 2002. Using the global positioning system to map disturbance patterns of forest harvesting machinery. Canadian Journal of Forest Research, 32(2), pp.310-319.

McDonald, T.P., Stokes, B.J. and Aust, W.M. 1995. Soil physical property changes after skidder traffic with varying tire widths. Journal of forest Engineering, 6(2), pp.41-50.

McFero Grace, J., Skaggs, R.W. and Cassel, D.K. 2006. Soil physical changes associated with forest harvesting operations on an organic soil. Soil Science Society of America Journal, 70(2), pp.503-509.

McNabb, D.H., Startsev, A.D. and Nguyen, H. 2001. Soil wetness and traffic level effects on bulk density and air-filled porosity of compacted boreal forest soils. Soil Science Society of America Journal, 65(4), pp.1238-1247.

McNabb, K.L., Miller, M.S., Lockaby, B.G., Stokes, B.J., Clawson, R.G., Stanturf, J.A. and Silva, J.N.M. 1997. Selection harvests in Amazonian rainforests: long-term impacts on soil properties. Forest Ecology and management, 93(1-2), pp.153-160.

Meyer, C., Lüscher, P. and Schulin, R. 2014. Recovery of forest soil from compaction in skid tracks planted with black alder (Alnus glutinosa (L.) Gaertn.). Soil and Tillage Research, 143, pp.7-16.

Mosaddeghi, M.R., Hajabbasi, M.A., Hemmat, A. and Afyuni, M. 2000. Soil compactibility as affected by soil moisture content and farmyard manure in central Iran. Soil and Tillage Research, 55(1-2), pp.87-97.

Naghdi, R. and Solgi, A. 2014. Effects of skidder passes and slope on soil disturbance in two soil water contents. Croatian Journal of Forest Engineering: Journal for Theory and Application of Forestry Engineering, 35(1), pp.73-80. 
Naghdi, R., Solgi, A., Zenner, E.K. and Behjou, F.K. 2018. Soil physical properties degrade further on skid trails in the year following operations. Journal of forestry research, 29(1), pp.93-101.

Najafi, A. 2010. Effects of skid trail slope and ground skidding on soil disturbance. Caspian Journal of Environmental Sciences, 8(1), pp.13-23.

Najafi, A., Solgi, A. and Sadeghi, S.H. 2009. Soil disturbance following four wheel rubber skidder logging on the steep trail in the north mountainous forest of Iran. Soil and Tillage Research, 103(1), pp.165-169.

Parkhurst, B.M., Aust, W.M., Bolding, M.C., Barrett, S.M. and Carter, E.A. 2018. Soil response to skidder trafficking and slash application. International journal of forest engineering, 29(1), pp.31-40.

Powers, R.F., Scott, D.A., Sanchez, F.G., Voldseth, R.A., Page-Dumroese, D., Elioff, J.D. and Stone, D.M. 2005. The North American long-term soil productivity experiment: findings from the first decade of research. Forest Ecology and Management, 220(1-3), pp.31-50.

Premer, M.I. 2015. Evaluating the long-term effects of logging residue removals in Great Lakes Aspen forests.

Quesnel, H.J. and Curran, M.P. 2000. Shelterwood harvesting in root-disease infected stands-post-harvest soil disturbance and compaction. Forest Ecology and Management, 133(1-2), pp.89-113.

Rab, M.A. and Dignan, P. 2002. The degree and extent of soil disturbance on operational logging coupes. In Lacey, S.T., Rab, M.A. and McCormack, R.J. (eds) Effect of forest harvesting on soil physical properties: Developing and evaluating meaningful soil indicators of sustainable forest management in southeastern Australia, pp. 43-55, Forest Wood Products Research and Development Corporation.

Reisinger, T.W., Pope, P.E. and Hammond, S.C. 1992. Natural recovery of compacted soils in an upland hardwood forest in Indiana. Northern Journal of Applied Forestry, 9(4), pp.138-141.

Rice, R.M. and Datzman, P.A. 1981. Erosion associated with cable and tractor logging in northwestern California. In In: Timothy RH Davies and Andrew J. Pearce (eds.), Erosion and Sediment Transport in Pacific Rim Steeplands, Proceedings of the Christchurch Symposium, 25-31 January 1981, Christchurch, New Zealand. Int. Assn. Hydrol. Sci. Pub. No. 132: 362-374. 
Rücknagel, J., Götze, P., Hofmann, B., Christen, O. and Marschall, K. 2013. The influence of soil gravel content on compaction behaviour and pre-compression stress. Geoderma, 209, pp.226-232.

Sawyers, B.C., Bolding, M.C., Aust, W.M. and Lakel, W.A. 2012. Effectiveness and implementation costs of overland skid trail closure techniques in the Virginia Piedmont. Journal of Soil and Water Conservation, 67(4), pp.300-310.

Simmons, F.C. 1951. Handbook for eastern timber harvesting. US Department of Agriculture, Forest Service, Northeastern Area, State \& Private Forestry.

Simpson, W. and TenWolde, A. 1999. Physical properties and moisture relations of wood. Chapter, 3, pp.2-1.

Smith, R.B., 1976. Soil disturbance, vegetative cover and regeneration on clearcuts in the Nelson Forest District, British Columbia.

Soane, B.D. and Van Ouwerkerk, C. 1995. Implications of soil compaction in crop production for the quality of the environment. Soil and Tillage Research, 35(1-2), pp.5-22.

Solgi, A., Najafi, A. and Sadeghi, S.H., 2014. Effects of traffic frequency and skid trail slope on surface runoff and sediment yield. International Journal of Forest Engineering, 25(2), pp.171-178.

Startsev, A.D. and McNabb, D.H. 2000. Effects of skidding on forest soil infiltration in west-central Alberta. Canadian Journal of Soil Science, 80(4), pp.617-624.

Stewart, V.I., Adams, W.A. and Abdulla, H.H.1970. Quantitative pedological studies on soils derived from Silurian mudstones: II. The relationship between stone content and the apparent density of the fine earth. Journal of Soil Science, 21(2), pp.248-255.

Stone, D.M. 2002. Logging options to minimize soil disturbance in the northern Lake States. Northern journal of Applied forestry, 19(3), pp.115-121.

Taylor, H. and Brar, G.S. 1991. Effect of soil compaction on root development. Soil and Tillage Research, 19(2-3), pp.111-119.

Torri, D., Poesen, J., Monaci, F. and Busoni, E. 1994. Rock fragment content and fine soil bulk density. Catena, 23(1-2), pp.65-71.

Vinson, J.A., Barrett, S.M., Aust, W.M. and Bolding, M.C. 2017. Evaluation of bladed skid trail closure methods in the ridge and valley region. Forest Science, 63(4), pp.432-440. 
Virginia Department of Forestry (VDOF). March, 2011. Virginia's forestry best management practices for water quality.

Wade, C.R., Bolding, M.C., Aust, W.M. and Lakel III, W.A. 2012. Comparison of five erosion control techniques for bladed skid trails in Virginia. Southern journal of applied forestry, 36(4), pp.191-197.

Wallbrink, P.J., Roddy, B.P. and Olley, J.M. 2002. A tracer budget quantifying soil redistribution on hillslopes after forest harvesting. Catena, 47(3), pp.179-201.

Webb, R.H., Steiger, J.W. and Wilshire, H.G. 1986. Recovery of Compacted Soils in Mojave Desert Ghost Towns 1. Soil Science Society of America Journal, 50(5), pp.13411344.

Williamson, J.R. and Neilsen, W.A. 2000. The influence of forest site on rate and extent of soil compaction and profile disturbance of skid trails during ground-based harvesting. Canadian Journal of Forest Research, 30(8), pp.1196-1205.

Zasada, J.C., Slaughter, C.W., Teutsch, C.E., Argyle, J.D. and Hill, W. 1987. Winter logging on the Tanana River flood plain in interior Alaska. Northern Journal of Applied Forestry, 4(1), pp.11-16.

Zenner, E.K., Fauskee, J.T., Berger, A.L. and Puettmann, K.J. 2007. Impacts of skidding traffic intensity on soil disturbance, soil recovery, and aspen regeneration in north central Minnesota. Northern Journal of Applied Forestry, 24(3), pp.177-183.

Zhao, Y., Krzic, M., Bulmer, C.E., Schmidt, M.G. and Simard, S.W. 2010. Relative bulk density as a measure of compaction and its influence on tree height. Canadian journal of forest research, 40(9), pp.1724-1735. 


\section{Appendices}

Appendix 1. 0-5 fine soil

\begin{tabular}{|l|r|r|r|r|}
\hline \multicolumn{5}{|c|}{ Type 3 Tests of Fixed Effects } \\
\hline Effect & Num DF & Den DF & F Value & Pr > F \\
\hline Plot(Traffic) & 15 & 226 & 2.92 & 0.0003 \\
\hline Traffic & 3 & 226 & 4.97 & 0.0023 \\
\hline SlashVol & 1 & 226 & 0.01 & 0.9430 \\
\hline
\end{tabular}

\begin{tabular}{|l|r|r|r|r|r|}
\hline \multicolumn{7}{|c|}{ Solution for Random Effects } \\
\hline Effect & Estimate & Std Err Pred & DF & t Value & Pr $>$ |t | \\
\hline RC_05 & 3.1506 & 0.2294 & 226 & 13.73 & $<.0001$ \\
\hline
\end{tabular}


Appendix 2. 0-5 full soil

\begin{tabular}{|l|r|r|r|r|}
\hline \multicolumn{5}{|c|}{ Type 3 Tests of Fixed Effects } \\
\hline Effect & Num DF & Den DF & F Value & Pr > F \\
\hline Plot(Traffic) & 15 & 226 & 3.16 & $<.0001$ \\
\hline Traffic & 3 & 226 & 5.06 & 0.0021 \\
\hline SlashVol & 1 & 226 & 0.01 & 0.9325 \\
\hline
\end{tabular}

\begin{tabular}{|l|r|r|r|r|r|}
\hline \multicolumn{7}{|c|}{ Solution for Random Effects } \\
\hline Effect & Estimate & Std Err Pred & DF & t Value & Pr > |t| \\
\hline RC_05 & 1.3805 & 0.2109 & 226 & 6.55 & $<.0001$ \\
\hline
\end{tabular}


Appendix 3. 5-10 fine soil

\begin{tabular}{|l|r|r|r|r|}
\hline \multicolumn{5}{|c|}{ Type 3 Tests of Fixed Effects } \\
\hline Effect & Num DF & Den DF & F Value & Pr > F \\
\hline Plot(Traffic) & 15 & 217 & 3.83 & $<.0001$ \\
\hline Traffic & 3 & 217 & 2.46 & 0.0637 \\
\hline SlashVol & 1 & 217 & 0.13 & 0.7186 \\
\hline
\end{tabular}

\begin{tabular}{|l|r|r|c|r|r|}
\hline \multicolumn{7}{|c|}{ Solution for Random Effects } \\
\hline Effect & Estimate & Std Err Pred & DF & t Value & Pr > |t| \\
\hline RC_510 & 3.1551 & 0.2061 & 217 & 15.31 & $<.0001$ \\
\hline
\end{tabular}


Appendix 4. 5-10 full soil

\begin{tabular}{|l|r|r|r|r|}
\hline \multicolumn{5}{|c|}{ Type 3 Tests of Fixed Effects } \\
\hline Effect & Num DF & Den DF & F Value & Pr > F \\
\hline Plot(Traffic) & 15 & 226 & 3.16 & $<.0001$ \\
\hline Traffic & 3 & 226 & 5.06 & 0.0021 \\
\hline SlashVol & 1 & 226 & 0.01 & 0.9325 \\
\hline
\end{tabular}

\begin{tabular}{|l|r|r|r|r|r|}
\hline \multicolumn{7}{|c|}{ Solution for Random Effects } \\
\hline Effect & Estimate & Std Err Pred & DF & t Value & Pr > |t| \\
\hline RC_05 & 1.3805 & 0.2109 & 226 & 6.55 & $<.0001$ \\
\hline
\end{tabular}


Appendix 5. 10-20 fine soil

\begin{tabular}{|l|r|r|r|r|}
\hline \multicolumn{5}{|c|}{ Type 3 Tests of Fixed Effects } \\
\hline Effect & Num DF & Den DF & F Value & Pr > F \\
\hline Plot(Traffic) & 15 & 225 & 5.15 & $<.0001$ \\
\hline Traffic & 3 & 225 & 6.20 & 0.0005 \\
\hline SlashVol & 1 & 225 & 0.62 & 0.4333 \\
\hline
\end{tabular}

\begin{tabular}{|l|r|r|r|r|r|}
\hline \multicolumn{5}{|c|}{ Solution for Random Effects } \\
\hline Effect & Estimate & Std Err Pred & DF & t Value & Pr $>$ |t $\mid$ \\
\hline RC_1020 & 3.2428 & 0.1615 & 225 & 20.08 & $<.0001$ \\
\hline
\end{tabular}


Appendix 6. 10-20 full soil

\begin{tabular}{|l|r|r|r|r|}
\hline \multicolumn{5}{|c|}{ Type 3 Tests of Fixed Effects } \\
\hline Effect & Num DF & Den DF & F Value & Pr > F \\
\hline Plot(Traffic) & 15 & 226 & 6.09 & $<.0001$ \\
\hline Traffic & 3 & 226 & 5.42 & 0.0013 \\
\hline SlashVol & 1 & 226 & 0.65 & 0.4205 \\
\hline
\end{tabular}

\begin{tabular}{|l|r|r|r|r|r|}
\hline \multicolumn{5}{|c|}{ Solution for Random Effects } \\
\hline Effect & Estimate & Std Err Pred & DF & $\mathbf{t}$ Value & $\operatorname{Pr}>|\mathbf{t}|$ \\
\hline RC_1020 & 1.1855 & 0.1399 & 226 & 8.47 & $<.0001$ \\
\hline
\end{tabular}


Appendix 7. Relation of eight and six wheeled machine on bulk density in 0-5 cm soil depth

\begin{tabular}{|c|c|c|c|c|c|c|}
\hline Anova: Single Factor & & & & & & \\
\hline \multicolumn{7}{|l|}{ SUMMARY } \\
\hline Groups & Count & Sum & Average & Variance & & \\
\hline $8 W$ & 132 & 164.8235 & 1.248663 & 0.050932 & & \\
\hline $6 W$ & 84 & 100.6058 & 1.197689 & 0.109928 & & \\
\hline \multicolumn{7}{|l|}{ ANOVA } \\
\hline Source of Variation & SS & $d f$ & $M S$ & $F$ & P-value & F crit \\
\hline Between Groups & 0.133385 & 1 & 0.133385 & 1.807043 & 0.180287 & 3.88528 \\
\hline Within Groups & 15.79614 & 214 & 0.073814 & & & \\
\hline Total & 15.92952 & 215 & & & & \\
\hline
\end{tabular}


Appendix 8. Relation of eight and six wheeled machine on bulk density in 5-10 cm soil depth

\begin{tabular}{|c|c|c|c|c|c|c|}
\hline Anova: Single Factor & & & & & & \\
\hline \multicolumn{7}{|l|}{ SUMMARY } \\
\hline Groups & Count & Sum & Average & Variance & & \\
\hline $8 W$ & 125 & 189.8607 & 1.518885 & 0.082283 & & \\
\hline $6 \mathrm{~W}$ & 82 & 121.7242 & 1.484441 & 0.14674 & & \\
\hline \multicolumn{7}{|l|}{ ANOVA } \\
\hline Source of Variation & SS & $d f$ & MS & $F$ & P-value & F crit \\
\hline Between Groups & 0.058747 & 1 & 0.058747 & 0.545209 & 0.461126 & 3.88722 \\
\hline Within Groups & 22.08907 & 205 & 0.107752 & & & \\
\hline Total & 22.14782 & 206 & & & & \\
\hline
\end{tabular}


Appendix 9. Relation of eight and six wheeled machine on bulk density in 10-20 cm soil depth

\begin{tabular}{|c|c|c|c|c|c|c|}
\hline Anova: Single Factor & & & & & & \\
\hline \multicolumn{7}{|l|}{ SUMMARY } \\
\hline Groups & Count & Sum & Average & Variance & & \\
\hline $8 W$ & 132 & 182.0239 & 1.378969 & 0.091216 & & \\
\hline $6 \mathrm{~W}$ & 84 & 131.4698 & 1.565116 & 0.135989 & & \\
\hline \multicolumn{7}{|l|}{ ANOVA } \\
\hline Source of Variation & SS & $d f$ & $M S$ & $F$ & $P$-value & F crit \\
\hline Between Groups & 1.778741 & 1 & 1.778741 & 16.38169 & $7.24 \mathrm{E}-05$ & 3.88528 \\
\hline Within Groups & 23.23634 & 214 & 0.108581 & & & \\
\hline Total & 25.01508 & 215 & & & & \\
\hline
\end{tabular}


Appendix 10. Comparison among different level of traffic intensities in Bonferroni at $0-5 \mathrm{~cm}$ depth for fine soil

\begin{tabular}{|l|l|l|r|r|r|r|r|r|r|}
\hline \multicolumn{10}{|c|}{ Differences of Least Squares Means } \\
\hline Effect & Traffic & Traffic & Estimate & $\begin{array}{r}\text { Standard } \\
\text { Error }\end{array}$ & DF & t Value & $\begin{array}{r}\text { Pr } \\
\text { |t }\end{array}$ & Adjustment & Adj P \\
\hline Traffic & High & Low & 0.05811 & 0.03255 & 226 & 1.79 & 0.0755 & Bonferroni & 0.4533 \\
\hline Traffic & High & Medium & 0.002439 & 0.03228 & 226 & 0.08 & 0.9398 & Bonferroni & 1.0000 \\
\hline Traffic & High & None & 0.1485 & 0.04313 & 226 & 3.44 & 0.0007 & Bonferroni & 0.0041 \\
\hline Traffic & Low & Medium & -0.05567 & 0.03190 & 226 & -1.75 & 0.0823 & Bonferroni & 0.4940 \\
\hline Traffic & Low & None & 0.09042 & 0.04181 & 226 & 2.16 & 0.0316 & Bonferroni & 0.1897 \\
\hline Traffic & Medium & None & 0.1461 & 0.04256 & 226 & 3.43 & 0.0007 & Bonferroni & 0.0043 \\
\hline
\end{tabular}


Appendix 11. Comparison among different level of traffic intensities in Bonferroni at 0-5 cm depth for full soil

\begin{tabular}{|l|l|l|r|r|r|r|r|r|r|}
\hline \multicolumn{7}{|c|}{ Differences of Least Squares Means } \\
\hline Effect & Traffic & Traffic & Estimate & $\begin{array}{r}\text { Standard } \\
\text { Error }\end{array}$ & DF & t Value & $\begin{array}{r}\text { Pr } \mathbf{r} \\
\text { |t }\end{array}$ & Adjustment & Adj P \\
\hline Traffic & High & Low & 0.05122 & 0.03018 & 226 & 1.70 & 0.0910 & Bonferroni & 0.5460 \\
\hline Traffic & High & Medium & 0.01131 & 0.02993 & 226 & 0.38 & 0.7060 & Bonferroni & 1.0000 \\
\hline Traffic & High & None & 0.1459 & 0.03999 & 226 & 3.65 & 0.0003 & Bonferroni & 0.0020 \\
\hline Traffic & Low & Medium & -0.03991 & 0.02958 & 226 & -1.35 & 0.1785 & Bonferroni & 1.0000 \\
\hline Traffic & Low & None & 0.09468 & 0.03876 & 226 & 2.44 & 0.0153 & Bonferroni & 0.0920 \\
\hline Traffic & Medium & None & 0.1346 & 0.03945 & 226 & 3.41 & 0.0008 & Bonferroni & 0.0046 \\
\hline
\end{tabular}


Appendix 12. Comparison among different level of traffic intensities in Bonferroni at $5-10 \mathrm{~cm}$ depth for fine soil

\begin{tabular}{|l|l|l|r|r|r|r|r|r|r|}
\hline \multicolumn{10}{|c|}{ Differences of Least Squares Means } \\
\hline Effect & Traffic & Traffic & Estimate & $\begin{array}{r}\text { Standard } \\
\text { Error }\end{array}$ & DF & t Value & $\begin{array}{r}\text { Pr } \mathbf{~} \\
\text { It }\end{array}$ & Adjustment & Adj P \\
\hline Traffic & High & Low & 0.07611 & 0.03785 & 217 & 2.01 & 0.0456 & Bonferroni & 0.2734 \\
\hline Traffic & High & Medium & 0.02510 & 0.03785 & 217 & 0.66 & 0.5079 & Bonferroni & 1.0000 \\
\hline Traffic & High & None & 0.1147 & 0.04960 & 217 & 2.31 & 0.0217 & Bonferroni & 0.1302 \\
\hline Traffic & Low & Medium & -0.05101 & 0.03627 & 217 & -1.41 & 0.1610 & Bonferroni & 0.9661 \\
\hline Traffic & Low & None & 0.03857 & 0.04652 & 217 & 0.83 & 0.4080 & Bonferroni & 1.0000 \\
\hline Traffic & Medium & None & 0.08959 & 0.04718 & 217 & 1.90 & 0.0589 & Bonferroni & 0.3534 \\
\hline
\end{tabular}


Appendix 13. Comparison among different level of traffic intensities in Bonferroni at $5-10 \mathrm{~cm}$ depth for full soil

\begin{tabular}{|l|l|l|r|r|r|r|r|r|r|}
\hline \multicolumn{9}{|c|}{ Differences of Least Squares Means } \\
\hline Effect & Traffic & Traffic & Estimate & $\begin{array}{r}\text { Standard } \\
\text { Error }\end{array}$ & DF & t Value & $\begin{array}{r}\text { Pr }> \\
\text { It| }\end{array}$ & Adjustment & Adj P \\
\hline Traffic & High & Low & 0.06346 & 0.03299 & 223 & 1.92 & 0.0557 & Bonferroni & 0.3340 \\
\hline Traffic & High & Medium & 0.02758 & 0.03261 & 223 & 0.85 & 0.3987 & Bonferroni & 1.0000 \\
\hline Traffic & High & None & 0.1057 & 0.04334 & 223 & 2.44 & 0.0155 & Bonferroni & 0.0932 \\
\hline Traffic & Low & Medium & -0.03588 & 0.03217 & 223 & -1.12 & 0.2660 & Bonferroni & 1.0000 \\
\hline Traffic & Low & None & 0.04222 & 0.04159 & 223 & 1.02 & 0.3111 & Bonferroni & 1.0000 \\
\hline Traffic & Medium & None & 0.07810 & 0.04193 & 223 & 1.86 & 0.0638 & Bonferroni & 0.3831 \\
\hline
\end{tabular}


Appendix 14. Comparison among different level of traffic intensities in Bonferroni at $10-20 \mathrm{~cm}$ depth for fine soil

\begin{tabular}{|l|l|l|r|r|r|r|r|r|r|}
\hline \multicolumn{9}{|c|}{ Differences of Least Squares Means } \\
\hline Effect & Traffic & Traffic & Estimate & $\begin{array}{r}\text { Standard } \\
\text { Error }\end{array}$ & DF & t Value & $\begin{array}{r}\text { Pr } \mathbf{~} \\
\text { It }\end{array}$ & Adjustment & Adj P \\
\hline Traffic & High & Low & 0.08914 & 0.02990 & 225 & 2.98 & 0.0032 & Bonferroni & 0.0191 \\
\hline Traffic & High & Medium & -0.02667 & 0.02976 & 225 & -0.90 & 0.3711 & Bonferroni & 1.0000 \\
\hline Traffic & High & None & 0.07189 & 0.03993 & 225 & 1.80 & 0.0731 & Bonferroni & 0.4387 \\
\hline Traffic & Low & Medium & -0.1158 & 0.02948 & 225 & -3.93 & 0.0001 & Bonferroni & 0.0007 \\
\hline Traffic & Low & None & -0.01724 & 0.03849 & 225 & -0.45 & 0.6546 & Bonferroni & 1.0000 \\
\hline Traffic & Medium & None & 0.09857 & 0.03894 & 225 & 2.53 & 0.0121 & Bonferroni & 0.0723 \\
\hline
\end{tabular}


Appendix 15. Comparison among different level of traffic intensities in Bonferroni at $10-20 \mathrm{~cm}$ depth for full soil

\begin{tabular}{|l|l|l|r|r|r|r|r|r|r|}
\hline \multicolumn{10}{|c|}{ Differences of Least Squares Means } \\
\hline Effect & Traffic & Traffic & Estimate & $\begin{array}{r}\text { Standard } \\
\text { Error }\end{array}$ & DF & t Value & $\begin{array}{r}\text { Pr } \\
\text { It }\end{array}$ & Adjustment & Adj P \\
\hline Traffic & High & Low & 0.07930 & 0.02711 & 226 & 2.93 & 0.0038 & Bonferroni & 0.0228 \\
\hline Traffic & High & Medium & -0.02033 & 0.02696 & 226 & -0.75 & 0.4516 & Bonferroni & 1.0000 \\
\hline Traffic & High & None & 0.05194 & 0.03591 & 226 & 1.45 & 0.1494 & Bonferroni & 0.8966 \\
\hline Traffic & Low & Medium & -0.09963 & 0.02671 & 226 & -3.73 & 0.0002 & Bonferroni & 0.0015 \\
\hline Traffic & Low & None & -0.02736 & 0.03457 & 226 & -0.79 & 0.4295 & Bonferroni & 1.0000 \\
\hline Traffic & Medium & None & 0.07227 & 0.03486 & 226 & 2.07 & 0.0393 & Bonferroni & 0.2358 \\
\hline
\end{tabular}


Appendix 16. Weather data of the research the site between February 2, 2017 to March 26, 2017

\begin{tabular}{|c|c|c|c|c|}
\hline Date & Snow & Snow Depth & $\begin{array}{c}\text { Temperature } \\
\text { MAX }\end{array}$ & $\begin{array}{c}\text { Temperature } \\
\text { MIN }\end{array}$ \\
\hline $2 / 6 / 2017$ & 1.2 & 19 & 18 & 11 \\
\hline $2 / 7 / 2017$ & 2.1 & 20 & 22 & 13 \\
\hline $2 / 8 / 2017$ & 9.6 & 27 & 24 & 6 \\
\hline $2 / 9 / 2017$ & 1.2 & 28 & 10 & -4 \\
\hline $2 / 10 / 2017$ & 0.4 & 27 & 16 & -4 \\
\hline $2 / 11 / 2017$ & 0 & 26 & 33 & 14 \\
\hline $2 / 12 / 2017$ & 0.4 & 25 & 33 & 21 \\
\hline $2 / 13 / 2017$ & 0 & 24 & 28 & 7 \\
\hline $2 / 14 / 2017$ & 0 & 22 & 45 & 20 \\
\hline $2 / 15 / 2017$ & 0.1 & 22 & 35 & 14 \\
\hline $2 / 16 / 2017$ & 0 & 21 & 18 & -1 \\
\hline $2 / 17 / 2017$ & 0 & 21 & 29 & 10 \\
\hline $2 / 18 / 2017$ & 0 & 18 & 55 & 29 \\
\hline $2 / 19 / 2017$ & 0 & 16 & 55 & 25 \\
\hline $2 / 20 / 2017$ & 0 & 13 & 51 & 29 \\
\hline $2 / 21 / 2017$ & 0 & 11 & 49 & 38 \\
\hline $2 / 22 / 2017$ & 0 & 9 & 56 & 35 \\
\hline $2 / 23 / 2017$ & 2.3 & 10 & 49 & 26 \\
\hline $2 / 24 / 2017$ & 0 & 10 & 32 & 19 \\
\hline $2 / 25 / 2017$ & 9.2 & 16 & 19 & 13 \\
\hline $2 / 26 / 2017$ & 1.2 & 16 & 20 & 9 \\
\hline $2 / 27 / 2017$ & 2.3 & 17 & 28 & -1 \\
\hline $2 / 28 / 2017$ & 0.7 & 15 & 40 & 13 \\
\hline $3 / 2 / 2017$ & 1.4 & 15 & 35 & -1 \\
\hline $3 / 3 / 2017$ & 0.1 & 15 & 23 & -6 \\
\hline $3 / 4 / 2017$ & 0 & 14 & 18 & -8 \\
\hline $3 / 5 / 2017$ & 0 & 13 & 34 & 11 \\
\hline $3 / 6 / 2017$ & 0 & 8 & 41 & 34 \\
\hline $3 / 7 / 2017$ & 0 & 3 & 50 & 27 \\
\hline $3 / 8 / 2017$ & 0.2 & 3 & 42 & 15 \\
\hline $3 / 9 / 2017$ & 2.2 & 4 & 19 & 14 \\
\hline $3 / 10 / 2017$ & 0 & 3 & 23 & 0 \\
\hline $3 / 11 / 2017$ & 0 & 3 & 8 & 0 \\
\hline $3 / 12 / 2017$ & 0 & 3 & 15 & 0 \\
\hline $3 / 13 / 2017$ & 0 & 3 & 18 & 2 \\
\hline $3 / 14 / 2017$ & 0 & 3 & 19 & -6 \\
\hline $3 / 15 / 2017$ & 0 & 3 & 28 & 1 \\
\hline
\end{tabular}




\begin{tabular}{|c|c|c|c|c|}
$3 / 16 / 2017$ & 0 & 3 & 28 & 2 \\
\hline $3 / 17 / 2017$ & 0 & 2 & 43 & 25 \\
\hline $3 / 18 / 2017$ & 1.3 & 2 & 33 & 30 \\
\hline $3 / 19 / 2017$ & 0 & 1 & 32 & 23 \\
\hline $3 / 20 / 2017$ & 0 & 1 & 40 & 24 \\
\hline $3 / 21 / 2017$ & 0 & 1 & 48 & 25 \\
\hline $3 / 22 / 2017$ & 0 & 1 & 26 & 2 \\
\hline $3 / 23 / 2017$ & 0 & 1 & 35 & 10 \\
\hline $3 / 24 / 2017$ & 0 & 1 & 32 & 26 \\
\hline $3 / 25 / 2017$ & 0 & 1 & 35 & 30 \\
\hline $3 / 26 / 2017$ & 0 & 0 & 33 & 28 \\
\hline
\end{tabular}


Appendix 17. Comparison between mean slash volumes of clearcut and partial cut

\begin{tabular}{|c|c|c|c|c|c|c|}
\hline Anova: Single Factor & & & & & & \\
\hline \multicolumn{7}{|l|}{ SUMMARY } \\
\hline Groups & Count & Sum & Average & Variance & & \\
\hline Partial cut & 109 & 1.61502 & 0.014817 & 0.009358 & & \\
\hline Clearcut & 109 & 3.81525 & 0.035002 & 0.036597 & & \\
\hline \multicolumn{7}{|l|}{ ANOVA } \\
\hline Source of Variation & SS & $d f$ & $M S$ & $F$ & P-value & F crit \\
\hline Between Groups & 0.022206 & 1 & 0.022206 & 0.966456 & 0.326665 & 3.88487 \\
\hline Within Groups & 4.963079 & 216 & 0.022977 & & & \\
\hline Total & 4.985286 & 217 & & & & \\
\hline
\end{tabular}

